Document downloaded from:

http://hdl.handle.net/10251/104870

This paper must be cited as:

A.Font; M.V.Borrachero; L.Soriano; J.Monzó; J.Payá (2017). Geopolymer eco-cellular concrete (GECC) based on fluid catalytic cracking catalyst residue (FCC) with addition of recycled aluminium foil powder. Journal of Cleaner Production. 168:1120-1131. doi:10.1016/j.jclepro.2017.09.110

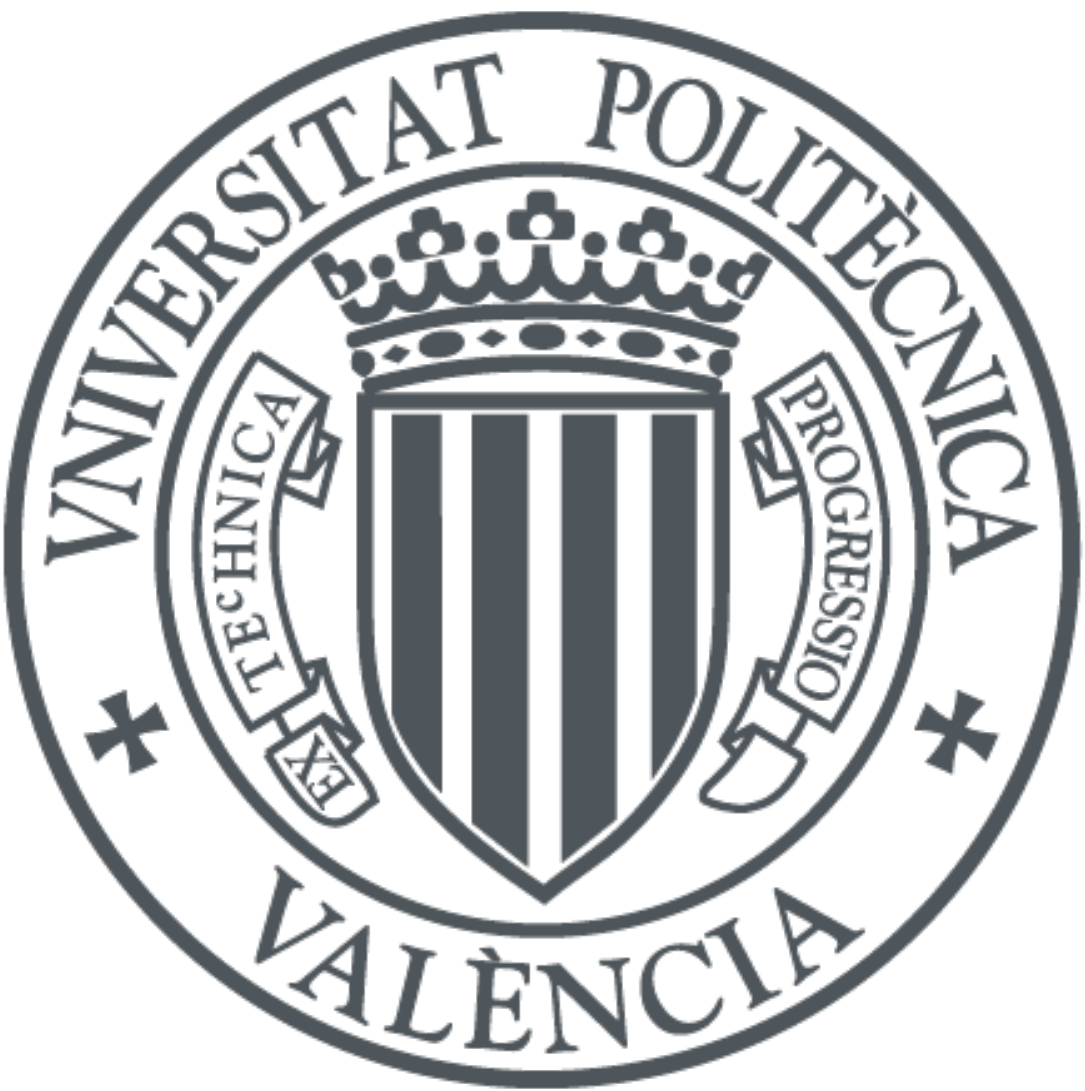

The final publication is available at

http://dx.doi.org/10.1016/j.jclepro.2017.09.110

Copyright Elsevier

Additional Information 


\title{
Geopolymer eco-cellular concrete (GECC) based on fluid catalytic cracking catalyst residue (FCC) with addition of recycled aluminium foil powder.
}

\author{
Alba Font, María Victoria Borrachero, Lourdes Soriano, José Monzó, Jordi Payá * \\ ICITECH - GIQUIMA - Grupo de Investigación en Química de los Materiales de \\ Construcción. Instituto de Ciencia y Tecnología del Hormigón, Universitat Politècnica de \\ València, Valencia, Spain. \\ * Corresponding author: jjpaya@cst.upv.es; tel: +34 963877569.
}

\begin{abstract}
This study presents a new cellular concrete design focused on the energy ecoefficiency and the sustainability concept: geopolymer eco-cellular concrete (GECC). Geopolymer systems made from alkali-activated fluid cracking catalyst residue (FCC) aerated by recycled aluminium foil powders $(R)$ were designed. Commercial aluminium powder (A) was also used as an aerating agent in GECC matrix and its effect was compared with traditional cellular concrete (TCC) made with ordinary Portland cement (OPC). The more alkaline medium of the GECC system improved the hydrogen reaction rate and consequently a higher efficiency in the pore matrix development can be found. Aluminium powder addition of $0.2 \%$ by mass of the precursor (FCC) was enough to yield cellular concrete with a natural density significantly lower than that found for TCC. The replacement of A by R made it possible to produce an alternative GECC in which the recycling of the waste aluminium has an important eco-efficiency role because its low cost and its energy saving function. Ground $R$ has less aeration effectiveness than A. However, when co-milling of FCC+R was carried out, advantageous performance GECC was attained. Very interesting properties were obtained for this material: good pore size and its proper distribution in the matrix, low natural density $\left(600-700 \mathrm{~kg} / \mathrm{m}^{3}\right)$, relatively high compressive strength (2.5-3.5 MPa), low open/closed porosity ratio (1.15) and the lowest thermal conductivity $(0.581 \mathrm{~W} / \mathrm{mK})$. This opens an interesting way of reusing both FCC as precursor and aluminium foil waste as an aerating agent in the preparation of new geopolymer eco-cellular concrete (GECC).
\end{abstract}

Keywords: Cellular concrete, geopolymers, ecoefficiency, waste valorisation.

\author{
Abbreviations: \\ TCC: Traditional cellular concrete \\ GECC: Geopolymer eco-cellular concrete \\ GFC: Geopolymer foam concrete \\ OPC: Ordinary Portland cement \\ FCC: Fluid catalytic catalyst \\ A: Commercial aluminium powder \\ $\mathrm{R}$ : Recycled aluminium foil \\ FCC $_{\mathrm{RM}}$ : Co-milled FCC+R blend
}


Traditional cellular concrete (TCC) is formed by ordinary Portland cement (OPC) paste (in some cases hydrated lime is added), with the addition of an inorganic (metallic powders) or an organic surfactant reagent (foaming agent). Commercial aluminium powder $(A)$ is the most used reagent in TCC production, and is oxidized immediately when it comes in contact with mixing water and the alkaline medium from OPC hydration, releasing hydrogen gas [1]. The result is a material characterized by its internal air-void structure (gas bubbles trapped in fresh state), which has been stabilized with an autoclaving-accelerated hardening treatment [2]. Owing to the air-void structure, this material has low density (values of 300 to 1400 $\mathrm{kg} / \mathrm{m}^{3}$ ) [3], low thermal conductivity (5-30\% of those measured on normal weight concrete) [4,5], great acoustic insulation, freeze-thaw resistance (to a defined saturation level) $[6,7]$ and high fire resistance (above $600^{\circ} \mathrm{C}$ keeping their properties unchanged) [8]. Due to these properties, TCC is a more durable material than traditional concrete [9-11]. Conversely, TCC is limited by its low mechanical strength and its high inelastic deformation [3]. The volume expansion of the fresh paste depends on the amount of aluminium powder that is added: hydrogen bubbles are homogeneously distributed in the paste, yielding a low density composite. Different materials can be designed in terms of density and strength: usually, higher density materials develop higher mechanical properties $[2,12]$.

There are several construction advantages in the use of TCC: a) its low density allows the reduction of the dead load in elements with low structural requirements, a faster building rate and lower haulage cost [5]; and b) its performance promotes its application as an insulation material for non- and semi-structural elements in building structures [3].

In general, TCC represents an interesting alternative material to improve the energy efficiency, climate comfort and sustainability in construction situations for either developed or undeveloped contexts. Nevertheless, TCC has some environmental and economic problems related with its raw materials and its fabrication process.

Driven by an ecological motivation, the production of this type of concrete requires a large amount of Portland cement $(70 \%$ by weight), the production of which is characterized by high energy demand, the consumption of non-renewable raw materials [13] and the emission of greenhouse gases (its manufacture contributes around $5-7 \%$ of global $\mathrm{CO}_{2}$ emissions) [14]. Alternative ways to produce cellular concrete by using new alkali-activated cement, commonly referred to as "geopolymer foam concrete (GFC)", are currently in the relatively early stages of study $[15,16]$. A complete review of GFC can be found in Zuhua Zhang et al. [17]. Specifically, there are several authors focused on GFC production with $A$ addition as the aerating agent: Jay G. Sanjayan et al. [15] as well as P. Hlavàcek et al. [18] have studied GFC based on alkali-activated fly ashes, R. Arellano Aguilar et al. [19] have combined metakaolin and fly ash binder in the geopolymeric mix. Also, the use of metakaolin-based binders was studied by P. Keawpapasson et al. [20], and $\mathrm{H}$. Emaisly et al. [21] have designed a non-autoclaved high strength cellular concrete from alkali-activated slag. The literature, however, does not show any work focused on GFC made from alkali-activated FCC. It is well known that this petroleum waste has a high pozzolanic reactivity [22-24] and now M.M Tashima et al. [25] have shown its great behaviour as an alkali-activated precursor.

A further negative aspect related to the energy saving is the curing treatment by autoclaving to obtain stable matrix with the medium compressive strength and low shrinkage needed in TCC design. The autoclaved method involves high temperature 
and high pressure conditions and consequently means both a great energy consumption and major economic impact. The new geopolymer cellular binders achieve stable matrix with curing treatments using a wet chamber and temperatures in the range $70-90^{\circ} \mathrm{C}$. R. Arellano Aguilar et al. [19] compared $20 \pm 2^{\circ} \mathrm{C}$ and $75 \pm 5^{\circ} \mathrm{C}$ curing temperatures and concluded that with the highest temperature the development of the compressive and flexural strengths was accelerated during the first day although in the long term the results for both curing treatments yielded the same performance. Jay G. Sanjayan et al. [15] kept the specimens for $24 \mathrm{~h}$ at room temperature until demoulding and then they were oven cured at $60^{\circ} \mathrm{C}$ for $24 \mathrm{~h}$. P. Hlavàcek et al. [18] maintained the specimens under laboratory conditions at $22^{\circ} \mathrm{C}$ for $2 \mathrm{~h}$ and subsequently put them in the oven for $12 \mathrm{~h}$. And $\mathrm{H}$. Emaisly et al. [21] replicated the curing regime of $2+3+6+3$, consisting of: pre-curing at $25 \pm 1{ }^{\circ} \mathrm{C}$ for $2 \mathrm{~h}$ to complete the gas production, ramping to the maximum temperature for $3 \mathrm{~h}$, soaking at the maximum temperature for $6 \mathrm{~h}$ and cooling down to room temperature for $3 \mathrm{~h}$. The maximum temperatures tested were 70,78 and $87^{\circ} \mathrm{C}$.

Finally, powdered aluminium also has a high environmental and economic impact as a component in TCC manufacture. To obtain a tonne of pure aluminium from bauxite requires $15000 \mathrm{kWh}$ of heat and electrical energy, and 5 tons of residues are produced [26]. Then, there are several methods for aluminium powder manufacture such as stamp milling, ball milling under dry conditions, wet ball milling, attrition milling and vibration milling [27]: all of these involve high environmental and economic costs. Thus, there arises the need to identify better alternatives in terms of environmental issues. The treatment and use of residual metallic aluminium could be an interesting alternative. Some authors have attempted to resolve this issue by reusing reactive waste. The following applications in TCC have been reported: E G. Araújo et al. [28] have investigated the possibility of incorporating aluminium recycled powders from recycled scrap in cellular concrete manufacture as an aerating agent. Erika Holt et al. [29] have tried to add residues from an energy pilot plant (gasification) that contains a substantial proportion of metallic aluminium. And more recently, Yuanming Song et al. [30] have worked with the use of residual ashes from municipal solid waste.

The goal of this contribution is to present a new environmentally friendly cellular concrete made from fluid catalytic cracking catalyst residue (FCC) as raw material and using recycled aluminium foil powders $(R)$ as the aerating agent, hereinafter called "geopolymer eco-cellular concrete (GECC)". First, a proper milling pretreatment of FCC and R is described, followed by volumetric tests to ensure the aerating effect of R. Then, the GECC specimens will be characterized: physical and mechanical characteristics, pore system structure, bulk density, porosity parameters and thermal conductivity.

\section{Materials and methods}

\subsection{Materials}

Ordinary Portland cement (OPC) was supplied by Lafarge (Puerto de Sagunto, Spain). FCC is a waste from the petroleum industry, and was supplied by the BP Oil Company from its plant in Grao Castellón (Spain). The chemical compositions of both OPC and FCC are summarized in Table 1 . Sodium hydroxide pellets (98\% purity) and sodium silicate $\left(8 \% \mathrm{Na}_{2} \mathrm{O}, 28 \% \mathrm{SiO}_{2}\right.$ and $\left.64 \% \mathrm{H}_{2} \mathrm{O}\right)$ were used for the preparation of the alkali activator and were supplied by Merck-Spain. 
Table 1 Chemical compositions of OPC and FCC (wt\%).

\begin{tabular}{cccccccccccc}
\hline \hline & $\mathrm{SiO}_{2}$ & $\mathrm{Al}_{2} \mathrm{O}_{3}$ & $\mathrm{Fe}_{2} \mathrm{O}_{3}$ & $\mathrm{CaO}$ & $\mathrm{MgO}$ & $\mathrm{SO}_{3}$ & $\mathrm{~K}_{2} \mathrm{O}$ & $\mathrm{Na}_{2} \mathrm{O}$ & $\mathrm{P}_{2} \mathrm{O}_{5}$ & $\mathrm{TiO}_{2}$ & LOI$^{*}$ \\
\hline OPC & 20.80 & 4.60 & 4.80 & 65.60 & 1.20 & 1.70 & 1.00 & 0.07 & - & - & 0.23 \\
$\mathrm{FCC}$ & 47.76 & 49.26 & 0.60 & 0.11 & 0.17 & 0.02 & 0.02 & 0.31 & 0.01 & 1.22 & 0.52 \\
\hline
\end{tabular}

*Loss on ignition

Two kinds of aluminium were tested: i) commercial aluminium powder (A) supplied by Schlenk Metallic Pigments $\mathrm{GmbH}$ which had a $30 \mu \mathrm{m}$ mean particle diameter; ii) recycled aluminium foil $(R)$ which was supplied by Agricultural-Forest Ecosystem Department from Universitat Politècnica de València. $R$ was recycled after using it to cover crop glass containers in autoclaving treatments.

\subsection{Experimental methodology}

The present investigation was carried out by an experimental procedure structured in four consecutive phases (Fig. 1). The first concerns the pre-treatment of raw materials: a milling procedure, in order to attain a suitable particle size and homogenize the particles for their appropriate use in cellular concrete fabrication. In the second phase, the reactivity of $A$ and $R$ was compared by a new and simple volumetric method to assess their aerating effect in the cement matrix. In the third phase some cellular concretes of GECC and TCC were designed and prepared. These were cured by different treatments and the physical characteristics of the resulting materials were studied and compared. In the last phase, some selected GECC systems aerated by each of the proposed methods were prepared and compared: the air-void structure was obtained by a combination of electronic and analytical techniques and the porosity parameters were obtained by hydric tests. Finally, the thermal conductivity of the samples was determined to ensure the proposed GECC insulation properties. The overview of the experimental procedure of the current work is shown in Fig. 1.

\subsection{Pre-treatment of raw materials}

The original FCC was milled for 20 minutes in a ball mill Gabrielli Mill-2 to attain a lower diameter and homogenize the particles. This is necessary to improve its reactivity in alkali medium and to encourage geopolymeric synthesis [22]. The particle sizes of both the original and milled FCC were measured by means of a Malvern Instruments Mastersizer 2000. Regarding R, since the production of TCC requires aluminium powders with fractions finer than 100 or $50 \mu \mathrm{m}$ in order to obtain the required mechanical properties [12] and appropriate air-void distribution, both cutting up and milling pre-treatments were necessary. By obtaining a finer particle diameter, the aluminium reaction in alkaline matrixes is improved. In this respect, firstly the $R$ had to be reduced into small sheets with diameters less than $4 \mathrm{~cm}$ by manual cutting. Then, these particles were processed by means of a food grinder Moulinex A320R1 of 0.6 litre capacity and 700 Watt power. The material was ground for 5 minutes, stopping for 5 seconds in every minute. The resulting particles had to be sieved and the particles passing af $125 \mu \mathrm{m}$ sieve were collected. The morphology of these particles was characterized by field emission scanning electron microscopy (FESEM) in an ULTRA 55-ZEISS microscope. Finally, with the aim of being able to obtain a lower size of $\mathrm{R}$ particles, the milling procedure was improved by means of blending the R into the FCC milling process. To this end, firstly, the R had to be reduced into sheets of $35 \mathrm{~mm}$ length and $4 \mathrm{~mm}$ width by means of a paper confetti cut shredder Rexel Prostyle of 1.2 litre capacity. These sheets of R ( $0.2 \%$ by weight) 
were included in the abovementioned FCC milling procedure, obtaining a new raw material for cellular concrete manufacture: $F C C_{R M}$. The particle size of the $F C C_{R M}$ was measured by means of the Malvern Instruments Mastersizer 2000. X-ray diffraction (XRD) patterns for ground $F C C$ and $F C C_{R M}$ were obtained by using a Bruker AXS D8 Advance in the Bragg's Angle (20) range of $5-70^{\circ}$.

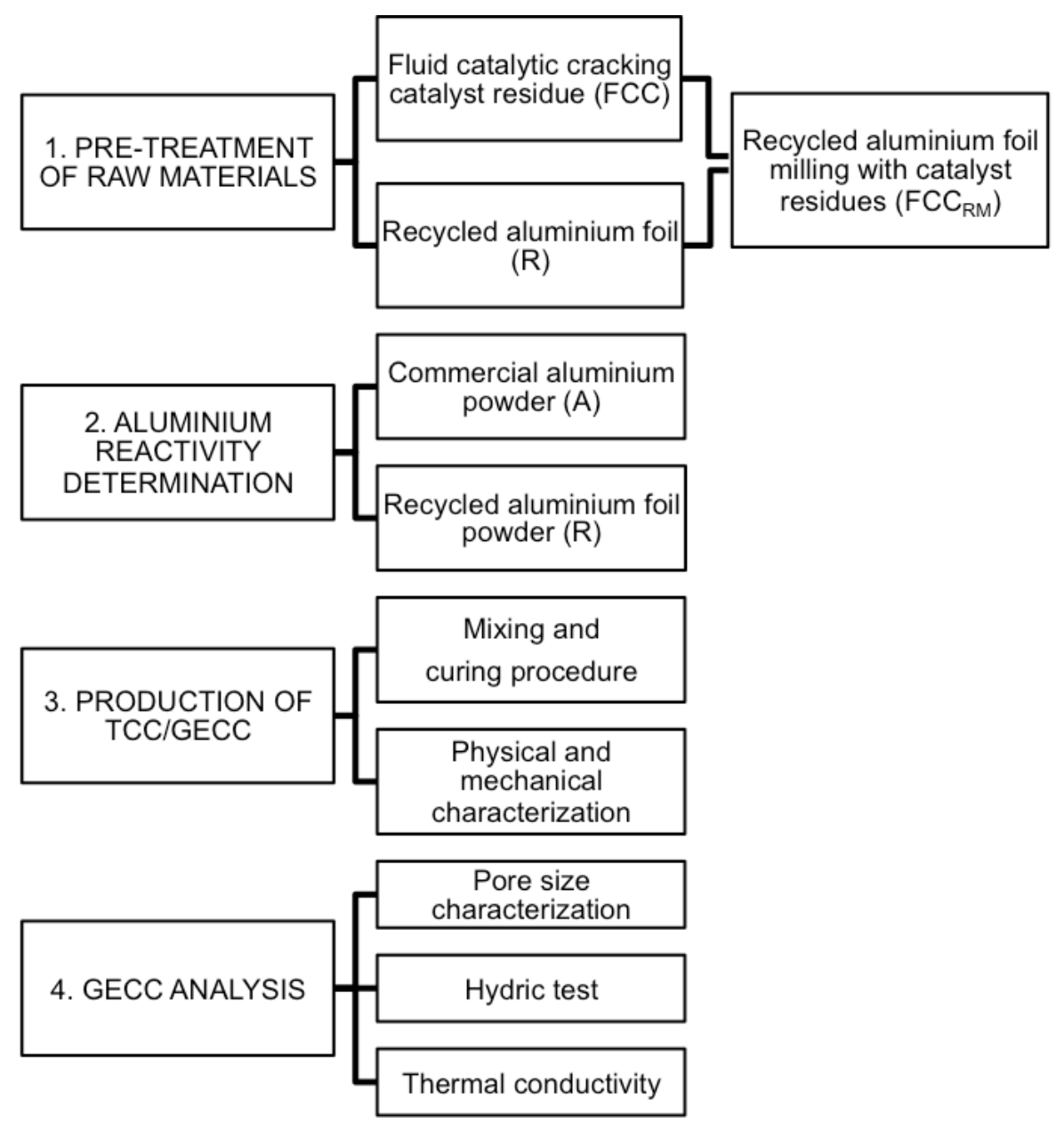

Fig. 1. Overview of experimental procedure of the current work

\subsection{Aluminium reactivity determination}

The aerating effect in the matrix of the cellular concrete was provided by the aluminium powder, which is oxidized when it comes into contact with mixing water or alkali solution and produces $\mathrm{H}_{2}$ gas. In this investigation the reactivity of $\mathrm{R}$ is determined by $\mathrm{H}_{2}$ generation measurements. Comparisons between the hydrogen generated by $\mathrm{A}$ and $\mathrm{R}$ were carried out. To develop this analysis, a new and simple gas volumetric method was designed, the set-up diagram of which is shown in Fig. 2. It is based on the Bernard calcimeter method [31], commonly used to determine carbonates in soils. The test measures the displacement of a water column by $\mathrm{H}_{2}$ gas when aluminium powder (either $\mathrm{A}$ or $\mathrm{R}$ ) comes into contact with a concentrated solution of $\mathrm{NaOH}(7.5 \mathrm{M})$, according to the following reaction (Equation 1): 


$$
\mathrm{Al}(\mathrm{s})+3 \mathrm{H}_{2} \mathrm{O}+\mathrm{OH}^{-}(\mathrm{ac}) \Rightarrow \mathrm{Al}(\mathrm{OH})_{4}^{-}(\mathrm{ac})+3 / 2 \mathrm{H}_{2}(\mathrm{~g})
$$

For given temperature $(T)$ and pressure $(P)$ values, the displaced $\mathrm{H}_{2}$ volume makes it possible to calculate the amount of aluminium consumed by applying the ideal gas Equation (2).

$$
\mathrm{P} \cdot \mathrm{V}=\mathrm{n}_{\mathrm{H} 2} \cdot R \cdot \mathrm{T}
$$

where $R$ is the ideal gas constant $\left(0.082 \mathrm{~L} \mathrm{~atm} \mathrm{~K}^{-1} \mathrm{~mol}^{-1}\right)$ and $\mathrm{n}_{\mathrm{H} 2}$ is the number of moles of $\mathrm{H}_{2}$. Thus, the mass of reactive aluminium $\left(\mathrm{m}_{\mathrm{Al}}\right)$ in the sample can be calculated as follows (Equation 3):

$$
m_{A l}=\frac{n_{H_{2}}}{3 / 2} * M_{(A l)}
$$

where $\mathrm{M}_{(\mathrm{Al})}$ is the molar mass of aluminium $\left(26.98 \mathrm{~g} \mathrm{~mol}^{-1}\right)$.

Three different aliquots, $10 \mathrm{mg}, 15 \mathrm{mg}$ and $20 \mathrm{mg}$, of each aluminium powder sample were tested and the ratio between the measured weight and the calculated weight by the amount of $\mathrm{H}_{2}$ liberated in the reaction was obtained.
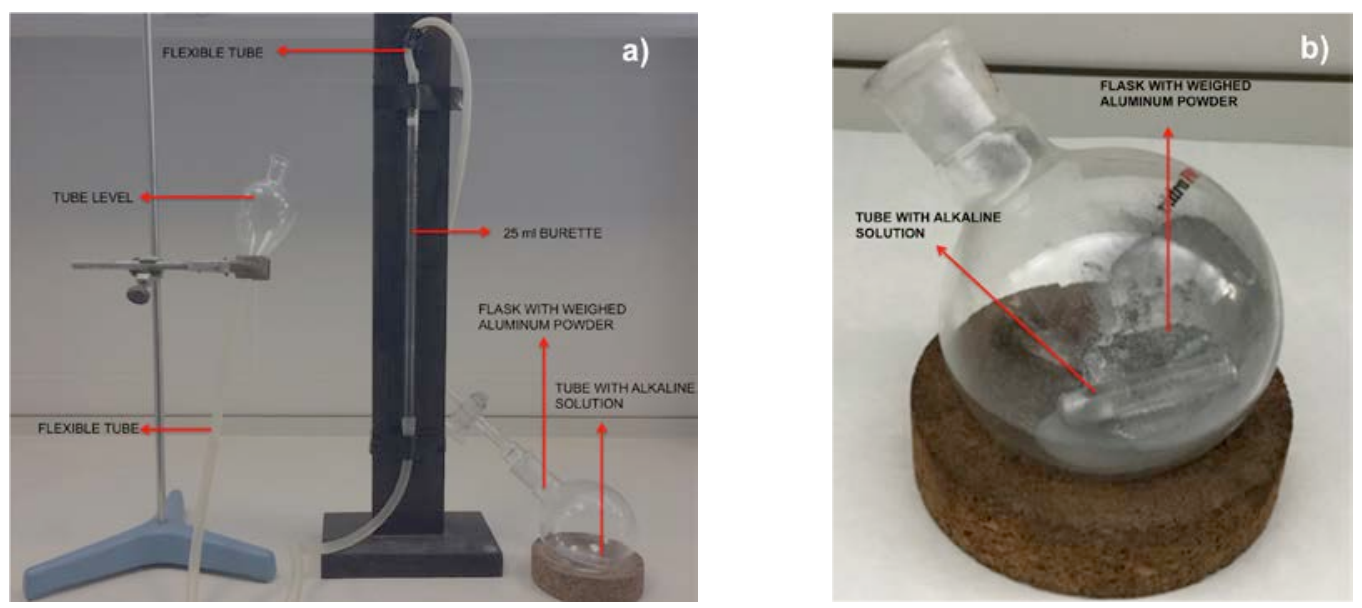

Fig. 2. Set-up diagram to perform hydrogen generation tests: a) general view; b) flask with weighed aluminium powder and tube with alkaline solution (7.5M NaOH) detail.

\subsection{Mixing and curing procedure}

Some trials were performed previously in order to make a first assessment of the material expansion and rheological behaviour to help the mix design. In general, for the production of both the GECC and TCC samples, raw materials (precursor) were dry-mixed with the corresponding aluminium powder and the mixture was then added into water (for TCC) or alkaline solution (for GECC).

In particular, the following dosages were studied:

- $\quad$ The reference system (TCC) was composed of OPC (binder, b), water in a $\mathrm{w} / \mathrm{b}$ ratio equal to 0.45 and $0.2 \%$ (by weight with respect to OPC) of $A$. The dry blend of OPC with $A$ was added to the water and mixed for 4 minutes. For each mix, six cube specimens of dimensions $4 \times 4 \times 4 \mathrm{~cm}^{3}$ were moulded and cured by different methods until testing.

- $\quad$ Regarding the GECC, three different dosages were designed using FCC as the mineral precursor (binder) and differing in the kind of added aluminium powder: i) $A$; ii) $R$; or iii) in the form of $F C C_{R M}$. In all of these, the w/b ratio was 
0.5 and the amount of aluminium was $0.2 \%$ (by weight with respect to the precursor). The alkaline activator had a $\mathrm{Na}^{+}$molality of 7.5 and the $\mathrm{SiO}_{2} / \mathrm{Na}_{2} \mathrm{O}$ molar ratio was 1.7. For each mix, six cube specimens of dimensions $4 \times 4 \times 4$ $\mathrm{cm}^{3}$ were moulded and cured by different methods until testing.

Due to the expansion process in the matrix of the pastes, no compacting treatment was carried out, in order to avoid the gas escaping from the cementing matrix.

The curing treatments were carried out: i) in a wet chamber $\left(23^{\circ} \mathrm{C}\right.$ and $\left.100 \% \mathrm{RH}\right)$; ii) in a thermal bath $\left(65^{\circ} \mathrm{C}\right)$ with $100 \% \mathrm{RH}$; and iii) with a combined method: 4 hours in the thermal bath until demoulding and then the wet chamber until testing. The free surface of the cubes had to be cut out with a saw blade just at the moment before demoulding.

The samples used in this study are named as $X Y c t$, where: $X$ is the type of cellular concrete ( $T$ in TCC case or $G$ in GECC case); $Y$ refers to the aerating agent added in the mixtures ( $A$ for commercial aluminium powder, $R$ for ground recycled aluminium foil and $\mathrm{FCC}_{\mathrm{RM}}$ for recycled aluminium foil milled with the precursor); $c$ is the curing treatment ( $w C$ for wet chamber, $t b$ for thermal bath and $\mathrm{cm}$ for combined method) and $t$ refers to the curing time until testing (1, 3 or 7 days, or 4 hours). More details relating to the specimens, mixing proportions and curing treatments are summarized in Table 2.

\subsection{Physical and mechanical characterization}

Considering the natural density as the volumetric mass density (mass per unit volume), it was determined by means of the weight of the cubic samples before compressive strength testing. The compression test was carried out by means of an INSTRON 3282 universal testing machine.

The natural density assessment and compression test were performed for six specimens of each paste dosage, and averages and standard deviation values were calculated.

\subsection{Pore system characterization}

The pore system characterization of the GECC was investigated with an organized test plan based on the combination of electronic and analytical techniques. To analyze the micropore structure by FESEM, a cube of each GECC mixture was crushed in a porcelain mortar. A small piece $(7-10 \mathrm{~mm})$ from the inner part of the cube was selected and immersed in acetone for 30 minutes and dried at $65^{\circ} \mathrm{C}$ for 40 minutes. FESEM micrographs of these samples covered with carbon were taken by an ULTRA 55-ZEISS electron microscope at 200x magnification, and the micropore diameters were measured. To determine the macropore structure, six $4 \times 4 \times 4 \mathrm{~cm}^{3}$ cubes of each GECC mixture were cut into slices $2 \mathrm{~cm}$ thick, perpendicular to the cast face, using a diamond rotary saw. The samples were observed by a Leica S8 APO optical microscope. Pictures were taken by a Leica DFC 420 digital camera and the images were processed using Leica LAS image analysis software. A magnification of $10 x$ was selected with a pixel representing 12 microns. A total of 24 images $\left(16 \mathrm{~cm}^{2}\right.$ per image) were captured for each mix (two images per each two internal surfaces). Finally, all of the cut-off surfaces (from the previous optical microscopy analysis) were submerged in a concentrated solution ( $0.4 \%$ by volume) of universal dye (colour vermilion 780) and universal solvent (302 NC), both from TKROM. Submerged samples were introduced into a desiccator connected to a vacuum pump to be suitable for the impregnation of empty pores. Finally, the surface was sanded with sandpaper. The pore diameter distribution histograms were 
obtained by measuring all the pore diameters in the original magnification using ImageJ software. Each image was digitized, processed with a few morphological operations (dilation, erosion, opening, closing and hole fill) to refine the shape of the objects, and finally converted into binary form.

\subsection{Hydric tests}

Hydric tests were carried out to determine the bulk density and porosity of the GECC and they were compared with the corresponding ones of TCC. To calculate the bulk density, the Archimedes method was used. Five $4 \times 4 \times 4 \mathrm{~cm}^{3}$ cubes of each studied material were dried for 24 hours in a furnace at $105^{\circ} \mathrm{C}$ and were then weighed to obtain their dry weight values. Then the samples were fully saturated by water immersion for 24 hours and weighed (saturated weight). In the saturation state the samples were weighed using a hydrostatic balance (submerged weight). Finally, to calculate the true density, a Le Chatelier flask was used after crushing $50 \mathrm{~g}$ of each sample.

\subsection{Thermal conductivity measurements}

A C-Therm TCi Thermal Conductivity Analyzer was employed to determine the thermal conductivity and effusivity of the samples. It employs a one-sided, interfacial heat reflectance sensor that applies a momentary constant heat source to the sample. The thermal conductivity and effusivity were measured directly, with no usercalibration or sample preparation and providing a detailed overview of the thermal characteristics of the sample. The test was carried out on four free surfaces of each cube with $16 \mathrm{~cm}^{2}$ area. Then the weighted average of those measures was calculated. 
Table 2 Summary of the specimen names, mixing proportions and curing treatments.

\begin{tabular}{|c|c|c|c|c|c|c|c|}
\hline & \multirow{2}{*}{$\begin{array}{l}\text { SAMPLES } \\
(\mathrm{XYCt})^{1}\end{array}$} & \multicolumn{2}{|c|}{ ALUMINIUM POWDER } & \multicolumn{2}{|c|}{ LIQUID PHASE } & \multirow{2}{*}{$\begin{array}{l}\text { CURING } \\
\text { METHOD }\end{array}$} & \multirow[b]{2}{*}{ TEST AGES } \\
\hline & & Type & $\% w t$ & $w / b$ & $\begin{array}{c}\text { Alkali } \\
\text { solution }{ }^{2}\end{array}$ & & \\
\hline \multirow{3}{*}{$\begin{array}{l}\text { TCC } \\
(\mathrm{OPC})\end{array}$} & $\begin{array}{l}\text { TAwc1d } \\
\text { TAwc3d } \\
\text { TAwc7d }\end{array}$ & \multirow{3}{*}{$\begin{array}{l}\text { Commercial } \\
\text { aluminium } \\
\text { A }\end{array}$} & \multirow{3}{*}{$0.2 \%$} & \multirow{3}{*}{0.45} & \multirow{3}{*}{ - } & $\begin{array}{l}\text { Wet chamber } \\
23^{\circ} \mathrm{C} 100 \% \mathrm{RH}\end{array}$ & $\begin{array}{l}24 \text { hours } \\
24 \text { hours till demoulding plus } 2 \text { days }=\underline{3 \text { DAYS }} \\
24 \text { hours till demoulding plus } 6 \text { days }=\underline{7 \text { DAYS }}\end{array}$ \\
\hline & $\begin{array}{l}\text { TAtb4h } \\
\text { TAtb1d } \\
\text { TAtb7d }\end{array}$ & & & & & $\begin{array}{l}\text { Thermal bath } \\
\quad 65^{\circ} \mathrm{C}\end{array}$ & $\begin{array}{l}4 \text { hours } \\
4 \text { hours till demoulding plus } 20 \text { hours }=24 \text { HOURS } \\
4 \text { hours till demoulding plus } 6 \text { days and } 20 \text { hours }=\underline{7 \text { DAYS }}\end{array}$ \\
\hline & TAcm7d & & & & & Combined method & 4 hours thermal bath plus 6 days wet chamber $=\underline{7 \text { DAYS }}$ \\
\hline \multirow{10}{*}{$\begin{array}{l}\text { GECC } \\
(\text { FCC })\end{array}$} & $\begin{array}{l}\text { GAwc1d } \\
\text { GAwc3d } \\
\text { GAwc7d }\end{array}$ & \multirow{3}{*}{$\begin{array}{l}\text { Commercial } \\
\text { aluminium } \\
\text { A }\end{array}$} & \multirow{3}{*}{$0.2 \%$} & \multirow{3}{*}{0.5} & \multirow{3}{*}{$7.5 / 1.7$} & $\begin{array}{l}\text { Wet chamber } \\
23^{\circ} \mathrm{C} 100 \% \mathrm{RH}\end{array}$ & $\begin{array}{l}24 \text { hours } \\
24 \text { hours till demoulding plus } 2 \text { days }=\underline{3 \text { DAYS }} \\
24 \text { hours till demoulding plus } 6 \text { days and } 20 \text { hours }=\underline{7} \\
\text { DAYS }\end{array}$ \\
\hline & $\begin{array}{l}\text { GAtb4h } \\
\text { GAtb1d } \\
\text { GAtb7d }\end{array}$ & & & & & $\begin{array}{l}\text { Thermal bath } \\
\quad 65^{\circ} \mathrm{C}\end{array}$ & $\begin{array}{l}4 \text { hours } \\
4 \text { hours till demoulding plus } 20 \text { hours }=24 \text { HOURS } \\
4 \text { hours till demoulding plus } 6 \text { days and } 20 \text { hours }=7 \text { DAYS }\end{array}$ \\
\hline & GAcm7d & & & & & Combined method & 4 hours till demoulding plus 6 days WC $=\underline{7 \text { DAYS }}$ \\
\hline & $\begin{array}{l}\text { GRwc1d } \\
\text { GRwc3d } \\
\text { GRwc7d }\end{array}$ & \multirow{3}{*}{$\begin{array}{l}\text { Recycled } \\
\text { aluminium foil } \\
\mathbf{R}\end{array}$} & \multirow{3}{*}{$0.2 \%$} & \multirow{3}{*}{0.5} & \multirow{3}{*}{$7.5 / 1.7$} & $\begin{array}{l}\text { Wet chamber } \\
23^{\circ} \mathrm{C} 100 \% \mathrm{RH}\end{array}$ & $\begin{array}{l}24 \text { hours } \\
24 \text { hours till demoulding plus } 2 \text { days }=3 \text { DAYS } \\
24 \text { hours till demoulding plus } 6 \text { days and } 20 \text { hours }=\underline{7} \\
\text { DAYS }\end{array}$ \\
\hline & $\begin{array}{l}\text { GRtb4h } \\
\text { GRtb1d } \\
\text { GRtb7d }\end{array}$ & & & & & $\begin{array}{l}\text { Thermal bath } \\
\quad 65^{\circ} \mathrm{C}\end{array}$ & $\begin{array}{l}4 \text { hours } \\
4 \text { hours till demoulding plus } 20 \text { hours }=24 \text { HOURS } \\
4 \text { hours till demoulding plus } 6 \text { days and } 20 \text { hours }=\underline{7 \text { DAYS }}\end{array}$ \\
\hline & GRem7d & & & & & Combined method & 4 hours till demoulding plus 6 days WC $=\underline{7 \text { DAYS }}$ \\
\hline & $\begin{array}{l}\text { GFCC }_{\text {RMWC1d }} \\
\text { GFCC } \\
\text { RMWC3d }\end{array}$ & \multirow{4}{*}{$\begin{array}{l}\text { Recycled aluminium } \\
\text { foil milled with the } \\
\text { precursor } \\
\text { FCC }_{\mathrm{RM}}\end{array}$} & \multirow{4}{*}{$0.2 \%$} & \multirow{4}{*}{0.5} & \multirow{4}{*}{$7.5 / 1.7$} & Wet chamber & $\begin{array}{l}24 \text { hours } \\
24 \text { hours till demoulding plus } 2 \text { days }=\underline{3 \text { DAYS }}\end{array}$ \\
\hline & GFCC $_{\text {RMWC7d }}$ & & & & & & $\begin{array}{l}24 \text { hours till demoulding plus } 6 \text { days and } 20 \text { hours }=\underline{7} \\
\text { DAYS }\end{array}$ \\
\hline & 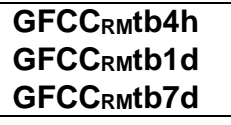 & & & & & $\begin{array}{l}\text { Thermal bath } \\
\quad 65^{\circ} \mathrm{C}\end{array}$ & $\begin{array}{l}4 \text { hours } \\
4 \text { hours till demoulding plus } 20 \text { hours }=\underline{24 \text { HOURS }} \\
4 \text { hours till demoulding plus } 6 \text { days and } 20 \text { hours }=\underline{7 \text { DAYS }}\end{array}$ \\
\hline & $\mathrm{GFCC}_{\mathrm{RM}} \mathrm{Cm} 7 \mathrm{~d}$ & & & & & Combined method & 4 hours till demoulding plus 6 days and 20 hours $=\underline{7 \text { DAYS }}$ \\
\hline
\end{tabular}

$1 X$ : type of cellular concrete (T for T CC; G for GECC); $Y$ : aerating agent added in mixtures (A: commercial aluminium powder; R: ground recycled aluminium foil; FCC $\mathrm{RM}_{\mathrm{R}}$ : recycled aluminium foil milled with the precursor); $c$ is the curing treatment (wC for wet chamber, tb for thermal bath and cm for combined method) and $t$ refers to the curing time until testing (1, 3 or 7 days, or 4 hours).

2 Composition of the solution is described as $\mathrm{Na}^{+}$molality $/ \mathrm{SiO}_{2} / \mathrm{Na}_{2} \mathrm{O}$ molar ratio 


\section{Results and discussion}

\subsection{Materials characterization}

After the milling pre-treatment of $\mathrm{R}$, the resulting particles less than $125 \mu \mathrm{m}$ were selected to use in TCC and GECC pastes as alternative aerating agents. To compare the size and morphology of $A$ and R, FESEM micrographs with the same magnification of each one (100x) were taken and are shown in Fig. 3. Fig. 3a presents the A particles characterized by a homogeneous distribution and a flake-like shape. Most of these particles had a diameter less than 50 microns and showed a flat surface. On the other hand, Fig. 3b shows ground R particles of less than $125 \mu \mathrm{m}$ after the milling process. They are shown as irregular chips with a varied morphology. Many particles showed an apparent size greater than $125 \mu \mathrm{m}$, which is due to the aspect ratio.

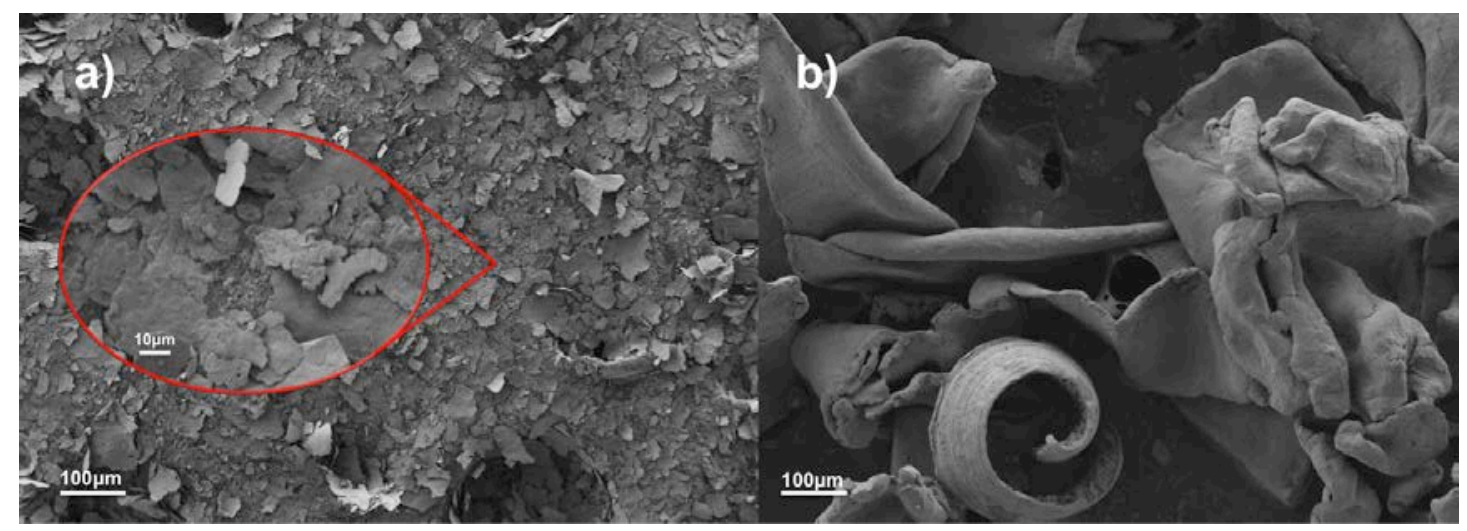

Fig. 3. FESEM micrographs of aerating agents: a) commercial aluminium powder $(A)$, the red line delimits an enlarged area; b) recycled aluminium foil powder $(R)$.

It is well known that a low average size of aluminium powder particles allows a more effective aerating reaction in the cement matrix. Thus, recycled aluminium $\mathrm{R}$ will be less effective in the preparation of cellular concrete.

The original FCC is not sufficiently fine for being activated by means of the alkaliactivation process. FCC had a milling pre-treatment and the particle size diameter was drastically reduced $(18.91 \mu \mathrm{m}$ for the ground sample vs $81.34 \mu \mathrm{m}$ for the original one). Additional granulometric parameters for both materials are listed in Table 3.

An FCC precursor containing recycled aluminium was obtained by milling a blend of FCC and small sheets of aluminium foil. The resulting $F_{C C} C_{R M}$ presented similar granulometric parameters to those obtained for the milling of original FCC (see Table 3). Certainly, the mean diameter of the aluminium particles would be much less than that obtained in the grinding/sieving treatment in which particles larger than $100 \mu \mathrm{m}$ were found. That means a probable improvement of the reaction of $R$ in alkaline medium, being more homogeneous and effective in the binder matrix.

Finally, Fig. 4 shows the XRD pattern of ground $F C C$ and $F C C_{R M}$. As might be expected, the X-ray diffractogram of ground FCC showed peaks corresponding to zeolite type faujasite $\left(\mathrm{Na}_{2} \mathrm{Al}_{2} \mathrm{Si}_{4} \mathrm{O}_{12} \cdot 8\left(\mathrm{H}_{2} \mathrm{O}\right)\right)$, as well as the minority presence of mullite $\left(\mathrm{Al}_{6} \mathrm{Si}_{2} \mathrm{O}_{13}\right)$. For the $\mathrm{FCC}_{\mathrm{RM}}$ diffractogram, there is a clear difference from the mineralogical composition, and the presence of metallic aluminium in the mineral precursor is evidenced by the peaks above $2 \theta=35^{\circ}$ corresponding to aluminium 
pattern: $38.45^{\circ}, 44.71^{\circ}$ and $65.09^{\circ}$ (corresponding to [111], [200] and [220] Miller planes), as highlighted with red in Fig. 4.

Table 3 Main granulometric parameters for catalyst residue (FCC) in its original and ground states, and recycled aluminium foil milling with catalyst residue ( $\left.F C C_{R M}\right)$.

\begin{tabular}{ccccc}
\hline & & \multicolumn{3}{c}{ Percentile Parameters } \\
\cline { 3 - 5 } Material & $\mathrm{d}_{\text {mean }}(\mu \mathrm{m})$ & $\mathrm{d}_{[0.1]}(\mu \mathrm{m})$ & $\mathrm{d}_{[0.5]}(\mu \mathrm{m})$ & $\mathrm{d}_{[0.9]}(\mu \mathrm{m})$ \\
\hline Original FCC & 81.34 & 47.63 & 79.36 & 131.65 \\
Milling FCC & 18.91 & 0.21 & 11.72 & 49.05 \\
FCC & 18.43 & 0.21 & 11.35 & 47.92
\end{tabular}

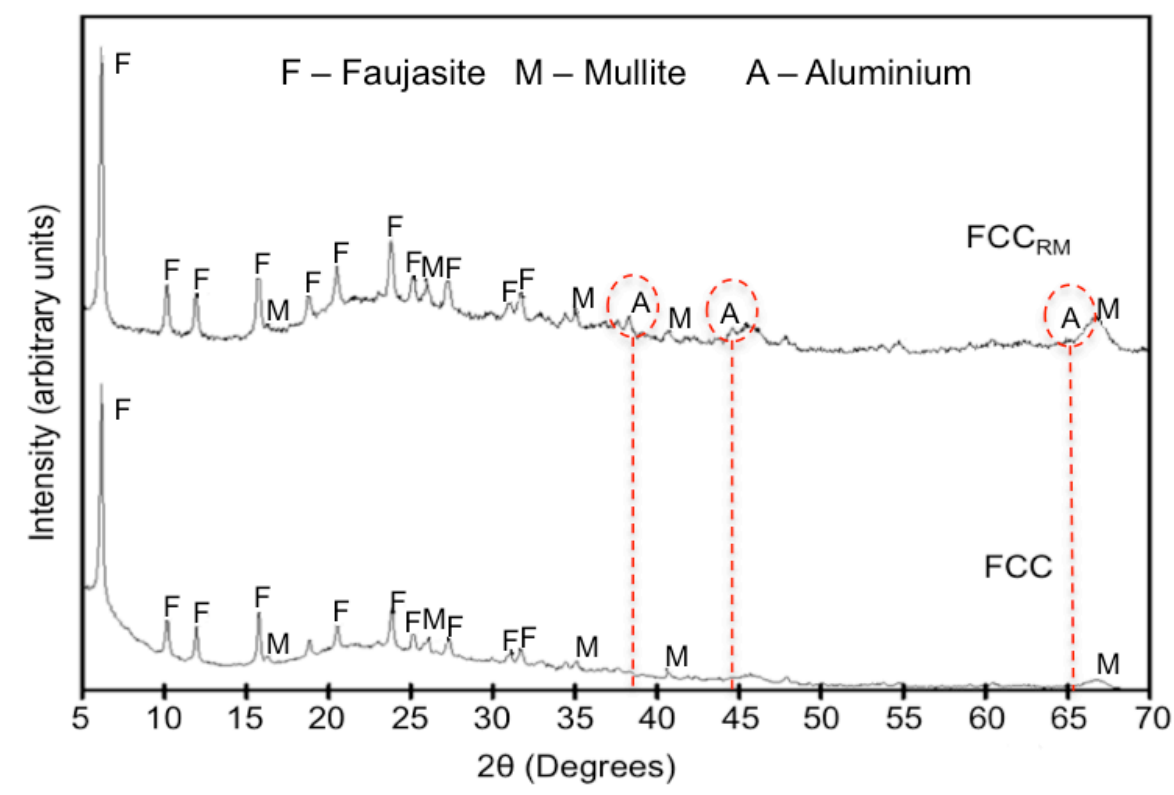

Fig. 4. XRD patterns for ground $F C C$ and $F C C_{R M}$.

\subsection{Aluminium reactivity determination}

The commercial aluminium powder $(\mathrm{A})$ used in this study had a minimum purity of $92 \%$. However, in taking this reagent as reference material in our study, initially $100 \%$ purity will be considered. Measurements of emitted hydrogen gas in the volumetric tests were carried out and the moles of $\mathrm{H}_{2}$ (Equation 2) and mass of aluminium (Equation 3) were calculated. Aliquots of 10, 15 and $20 \mathrm{mg}$ of $\mathrm{A}$ were tested and the theoretical (assuming 100\% purity) and experimental aluminium contents were assessed. As can be seen in Fig. 5, a good correlation between the calculated and experimental amounts of aluminium was achieved. The results obtained from $10 \mathrm{mg}$ samples deviated from the $\mathrm{x}=\mathrm{y}$ line, suggesting that for the lowest mass selected the accuracy of the measurements has a significant influence (lower hydrogen volume, lower accuracy in the weighing of sample). The results demonstrated that the purity of $A$ was much greater than the minimum purity declared by the company. 


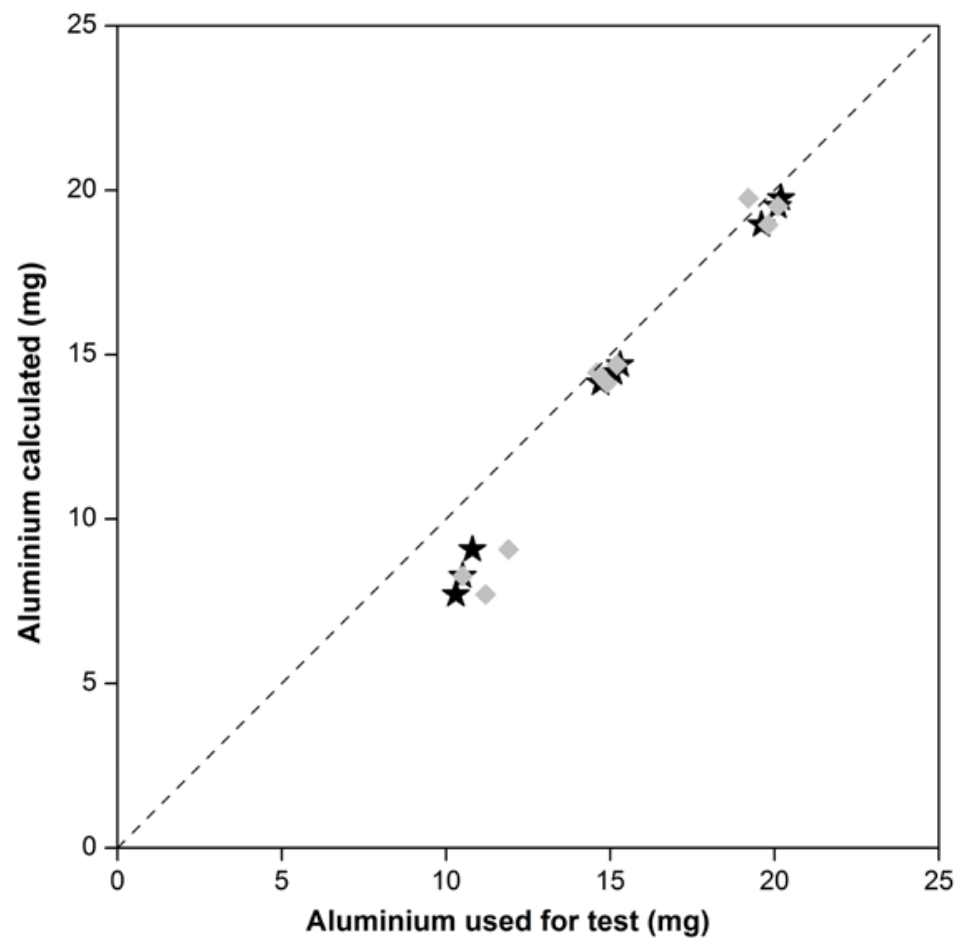

Fig. 5. Results of aluminium powder reaction test: aluminium used for each test with respect to aluminium calculated (Key: $\star$ : commercial aluminium powder; $\bullet$ : recycled foil; ---: $x=y$ line).

In general, the values of aluminium calculated in this designed gas volumetric method are lower compared to the aluminium mass used. The correspondence between the aluminium used for the test and the aluminium calculated is highest with the greatest amount of tested aluminium. With the weighed values of $10 \mathrm{mg}$, the results of the aluminium calculated are clearly displaced below the $x=y$ line. As the amount of aluminium used in the measurements increases to $15 \mathrm{mg}$ the deviation is lower.

Finally, when the $20 \mathrm{mg}$ weighed value is used the deviation is almost negligible. This may be for two reasons: the first is that $\mathrm{H}_{2}$ is a very diffusive gas and consequently a slight amount of the gas is lost through the assembly joints; secondly the purity of the aluminium is probably slightly lower than $100 \%$. The latter is related to the oxidation of the external surface of the aluminium particles (the formation of a thin passivation layer of aluminium oxide or hydroxyl oxide). The purity of the recycled aluminium foil was unknown. However, when the volumetric measurements are compared to those obtained for commercial aluminium powder, very similar values were obtained. This means that the purity of recycled aluminium is also very high, close to $100 \%$.

In general terms, the results reveal the applicability of the designed test in order to determine the purity of aluminium samples. Additionally, this method makes it possible to calculate the maximum volume of hydrogen generated in the cellular concrete. 


\subsection{Physical and mechanical characterization}

The natural density and compressive strength of both TCC and GECC concrete aerated by the addition of $A$ and cured by the three proposed methods are shown in Table 4.

Table 4 Natural density and compressive strength of TCC (TA samples) and GECC (GA samples) aerated concretes with commercial aluminium powder (A).

\begin{tabular}{|c|c|c|c|c|c|c|c|c|c|c|c|c|c|c|}
\hline \multirow[b]{4}{*}{$\begin{array}{l}\text { Natural } \\
\text { density }\left(\mathrm{kg} / \mathrm{m}^{3}\right)\end{array}$} & \multicolumn{7}{|c|}{ TA samples (prepared with OPC) } & \multicolumn{7}{|c|}{ GA samples (prepared with FCC) } \\
\hline & \multicolumn{3}{|c|}{$w^{1}$} & \multicolumn{3}{|c|}{ tb $^{2}$} & \multirow{2}{*}{$\frac{\mathrm{cm}^{3}}{7 \mathrm{~d}}$} & \multicolumn{3}{|c|}{$w^{1}$} & \multicolumn{3}{|c|}{ tb 2} & \multirow{2}{*}{$\frac{\mathrm{cm}^{3}}{7 \mathrm{~d}}$} \\
\hline & $1 d$ & 3d & $7 d$ & $4 \mathrm{~h}$ & 1d & $7 d$ & & $1 d$ & $3 d$ & $7 d$ & $4 h$ & $1 d$ & $7 d$ & \\
\hline & 912 & 909 & 908 & 669 & 667 & 666 & 642 & 592 & 590 & 590 & 532 & 531 & 528 & 510 \\
\hline $\begin{array}{l}\text { Standard } \\
\text { deviation }\end{array}$ & 8 & 6 & 4 & 5 & 5 & 5 & 8 & 7 & 6 & 6 & 6 & 7 & 5 & 9 \\
\hline $\begin{array}{l}\text { Compressive } \\
\text { strength (MPa) }\end{array}$ & 1.75 & 2.24 & 2.60 & 0.96 & 1.45 & 2.03 & 1.94 & 0.50 & 0.81 & 1.83 & 0.67 & 2.04 & 2.12 & 2.19 \\
\hline $\begin{array}{l}\text { Standard } \\
\text { deviation }\end{array}$ & 0.4 & 0.12 & 0.13 & 0.12 & 0.35 & 0.34 & 0.04 & 0.04 & 0.03 & 0.11 & 0.13 & 0.29 & 0.38 & 0.17 \\
\hline
\end{tabular}

1. wc: wet chamber at $23^{\circ} \mathrm{C}$ and $100 \% \mathrm{RH} ; 2$. tb: thermal bath at $65^{\circ} \mathrm{C} ; 3 . \mathrm{cm}$ : combined method

For the TCC, the lowest natural density was obtained in samples cured by the combined method $\left(642 \mathrm{~kg} / \mathrm{m}^{3}\right)$ and it yielded the lowest strength after 7 days of curing (1.94 MPa). TCC cured in a thermal bath had a similar natural density, slightly higher $\left(666 \mathrm{~kg} / \mathrm{m}^{3}\right)$ than that from the combined method. However, the material cured in the wet chamber conditions developed a higher density, which is related to the expansion rate in fresh conditions. At $20^{\circ} \mathrm{C}$, the hydrogen evolution into the OPC matrix is slow and setting of the system is produced before complete oxidation of the aluminium. In these conditions, the evolved gas after setting escaped without producing expansion.

In the case of GECC, the lowest natural density value was also obtained by means of the combined method $\left(510 \mathrm{~kg} / \mathrm{m}^{3}\right)$, but in this case it yielded the highest strength (2.19 $\mathrm{MPa}$ at 7 days). However, the difference in density with respect to the wet chamber curing method is significantly less among GECC specimens in comparison to TCC specimens. This means that in this medium, the transformation rate of aluminium is faster than that produced in the OPC medium. Thus, a larger part of the hydrogen evolved before setting, trapping the gas bubbles in the matrix. Serendipitously, the strength developed after 7 days of curing was the highest, suggesting that the cementitious products and gas bubbles were better spatially distributed. Generally, the geopolymeric systems allow lower natural density values to be obtained compared to traditional systems. Due to the higher alkaline medium in GECC, the aluminium powder reaction is faster and more aggressive. In addition, as can be observed, the highest compressive strengths were obtained for GECC cured in the thermal bath $(2.12 \mathrm{MPa})$ and the combined method, which confirms that the great polymerization of the geopolymer systems at mildly elevated temperature conditions is not affected by the aeration process.

On the whole, regardless of the curing method, for all mixtures the compressive strength rises with increasing curing time. 
Taking into account the same aluminium powder dosage, when the curing method was the wet chamber, the average natural densities for 1 day of curing were 912 $\mathrm{kg} / \mathrm{m}^{3}$ for TCC and $592 \mathrm{~kg} / \mathrm{m}^{3}$ for GECC, respectively. For these samples, after 7 days of curing, the gain of compressive strength compared to the values after 1 and 3 days of curing was $21.9 \%$ and $13.8 \%$ for TCC and $38.3 \%$ and $55.7 \%$ for GECC respectively.

On the other hand, when the samples were cured in the thermal bath at $65^{\circ} \mathrm{C}$, the average natural density at 4 hours of curing were $669 \mathrm{~kg} / \mathrm{m}^{3}$ for TCC and $532 \mathrm{~kg} / \mathrm{m}^{3}$ for GCC, respectively. For these samples, after 7 days of curing the gain of compressive strength compared to the values after 4 hours and 3 days of curing were $33.8 \%$ and $28.6 \%$ for TCC and $67.2 \%$ and $3.8 \%$ for GCC respectively.

There is a significant difference in the natural density values for TCC samples if wet chamber or thermal bath curing conditions are used. In contrast, the effect of the curing method for GECC samples had less influence on the natural density. The percentage decrease of the average natural density from the wet chamber to the thermal bath treatment was $26.7 \%$ for TCC and $10.3 \%$ for GECC respectively. This reveals the high temperature requirement in traditional TCC systems to allow a suitable generation and entrapment of hydrogen bubbles. Even so, in the case of the compressive strength development, there were percentage differences after 7 days of curing between the wet chamber and thermal bath treatments: $21.9 \%$ reduction for TCC and $34.9 \%$ gain for GCC respectively. Advantageously, for GECC systems, the evolution of gas generation and entrapping was successful for both curing treatments.

The results for the combined method of curing in both GECC and TCC systems reveal that is not necessary to keep the thermal bath conditions for more than 4 hours to improve the physical and mechanical features.

In general, since the structural requirements of cellular concrete are not very high, and taking into account the TCC results, the manufacturing of GECC aerated by commercial aluminium powder was successful in terms of natural density and compressive strength when the samples were cured at room temperature.

Regarding the use of $\mathrm{R}$ in geopolymer systems, the natural density and compressive strength values of the different mixtures are shown in Table 5.

Table 5 Natural density and compressive strength of GECC aerated concretes with recycled aluminium foil (R) and for GFCC $\mathrm{RM}$.

\begin{tabular}{|c|c|c|c|c|c|c|c|c|c|c|c|c|c|c|}
\hline & \multicolumn{7}{|c|}{ GR samples } & \multicolumn{7}{|c|}{ GFCC $_{\mathrm{RM}}$ samples } \\
\hline & \multicolumn{3}{|c|}{$w^{1}{ }^{1}$} & \multicolumn{3}{|c|}{$\mathrm{tb}^{2}$} & \multirow{2}{*}{$\frac{\mathrm{cm}^{3}}{7 \mathrm{~d}}$} & \multicolumn{3}{|c|}{$w{ }^{1}$} & \multicolumn{3}{|c|}{$\mathrm{tb}_{2}$} & \multirow{2}{*}{$\frac{\mathrm{cm}^{3}}{7 d^{3}}$} \\
\hline & $1 d$ & $3 d$ & $7 d$ & $4 h$ & $1 d$ & $7 d$ & & $1 d$ & $3 d$ & $7 d$ & $4 h$ & $1 d$ & $7 d$ & \\
\hline $\begin{array}{l}\text { Natural } \\
\text { density }\left(\mathrm{kg} / \mathrm{m}^{3}\right)\end{array}$ & 987 & 985 & 983 & 954 & 950 & 950 & 950 & 695 & 693 & 690 & 637 & 637 & 635 & 633 \\
\hline $\begin{array}{l}\text { Standard } \\
\text { deviation }\end{array}$ & 4.92 & 4.60 & 4.58 & 3.65 & 4.91 & 5.85 & 9.13 & 8.92 & 9.92 & 9.24 & 5.17 & 5.40 & 5.30 & 5.47 \\
\hline $\begin{array}{l}\text { Compressive } \\
\text { strength (MPa) }\end{array}$ & 0.74 & 1.66 & 3.56 & 1.03 & 1.86 & 3.54 & 3.89 & 0.35 & 1.67 & 3.50 & 0.51 & 1.36 & 2.87 & 2.51 \\
\hline $\begin{array}{l}\text { Standard } \\
\text { deviation }\end{array}$ & 0.10 & 0.27 & 0.23 & 0.34 & 0.14 & 0.47 & 0.55 & 0.04 & 0.34 & 0.23 & 0.07 & 0.10 & 0.22 & 0.30 \\
\hline
\end{tabular}


By using ground $\mathrm{R}$ as the agent to aerate the geopolymeric matrix (GR mixtures), natural density values of about $1000 \mathrm{~kg} / \mathrm{m}^{3}$ for all of the proposed curing methods were obtained and there were no significant differences among them. After 7 days of curing, the natural density was in the range $950-983 \mathrm{~kg} / \mathrm{m}^{3}$, a range significantly higher than that found for GA $\left(510-590 \mathrm{~kg} / \mathrm{m}^{3}\right)$. Since the R particle size was not fine enough, the relatively high density values may have been due to three different situations: i) a complete aluminium reaction was not possible and the aeration results were insufficient; ii) the reaction took place too fast and the hydrogen diffused before the paste matrix had enough consistency to entrap it; iii) a combination of the above two situations.

A better behaviour was observed when $R$ was previously blended into the FCC milling treatment (mixtures $\mathrm{GFCC}_{\mathrm{RM}}$ ) and the average natural densities for the wet chamber, thermal bath and combined method were 690,635 and $633 \mathrm{~kg} / \mathrm{m}^{3}$ respectively, values very close to those found for the GA mixtures.

Figure 6 shows both relative coefficients related to natural density and compressive strength. In terms of natural density, the ratio $\left(\varphi_{d}\right)$ was obtained according to Equation (3), where a $\varphi_{d}$ value lower than 1 means that the aeration was more effective than for commercial aluminium $A$. In terms of strength, the ratio $\left(\theta_{\mathrm{s}}\right)$ was obtained according to Equation (4), where a $\theta_{\mathrm{s}}$ value higher than 1 means a more resistant structure for recycled aluminium.

$$
\varphi_{d}=\frac{\rho_{A}}{\rho_{R}}
$$

where $\rho_{A}$ is the natural density for GECC aerated with $A$, and $\rho_{R}$ is the density when aerated with $\mathrm{R}$ or with $\mathrm{FCC}_{\mathrm{RM}}$.

$$
\theta_{s}=\frac{r_{R}}{r_{A}}
$$

where $\gamma_{A}$ is the compressive strength for GECC aerated with $A$, and $\gamma_{R}$ is the strength when aerated with $\mathrm{R}$ or with $\mathrm{FCC}_{\mathrm{RM}}$.

As can be seen, the natural density coefficients $\left(\varphi_{d}\right)$ were close to unity for $\mathrm{GFCC}_{\mathrm{RM}}$ mixtures, whereas for GR the values were close to 0.5 . This indicates the excellent effectiveness of the $\mathrm{FCC}_{\mathrm{RM}}$ system aeration. The values of $\varphi_{d}$ decrease slightly with the curing temperature, for both $\mathrm{GR}$ and $\mathrm{GFCC}_{\mathrm{RM}}$ samples.

The compressive strength coefficients were greater than those in all the recycled aluminium containing mixtures. Obviously, this behaviour indicates that the compressive strength of GECC by the addition of R (as GR or as GFCC $_{R M}$ ) was greater than GECC aerated by A. 
It is noticeable that in the case of the wet chamber cured samples for the GFCC $\mathrm{RM}_{\mathrm{R}}$ system, the natural density was in the same range as that obtained in the GA system $\left(\varphi_{d}=0.99\right)$, whereas a significantly higher compressive strength $\left(\theta_{s}=1.91\right)$ was achieved. This means that the new proposal for preparing the binder by grinding FCC and $\mathrm{R}$ together represents an excellent alternative in terms of physical/mechanical properties. Additionally, this preparation procedure makes it possible to have a very good homogenization of the recycled aluminium, taking advantage of the FCC milling. This proposal does not increment the complexity of the process.
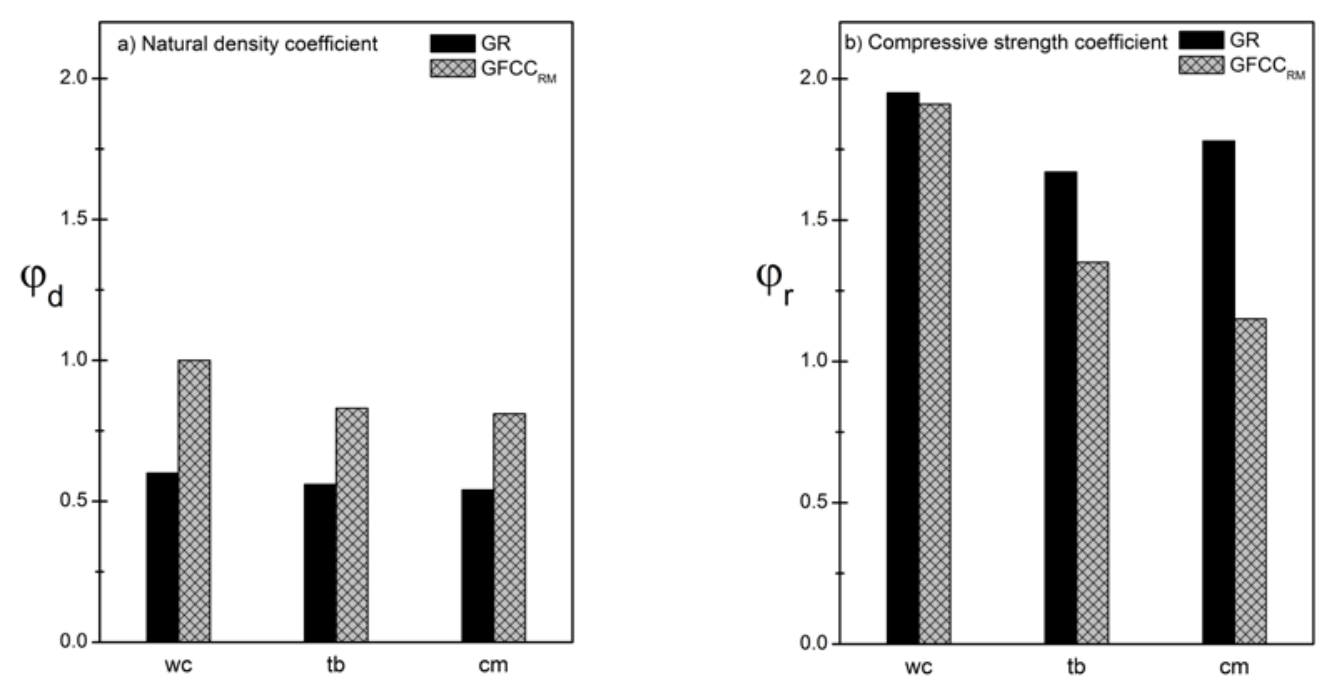

Fig. 6. Comparisons between commercial aluminium aerated systems and recycled aluminium foil (R) aerated systems: a) natural density coefficient $\left(\varphi_{d}\right)$; b) compressive strength coefficient $\left(\theta_{s}\right)$.

\subsection{Pore system characterization}

There have been several investigations dealing with the pore system of TCC and three different classifications have been proposed: i) artificial air pores, intercluster and interparticle pores; ii) macropores formed due to the expansion of the mass caused by aeration and micropores which appear in the walls between the macropores; and iii) microcapillaries $(<50 \mathrm{~nm})$, macrocapillaries ( $>50 \mathrm{~nm}$ to $50 \mu \mathrm{m}$ ) and artificial air pores $(>50 \mu \mathrm{m})[21]$.

K. Ramamurthy et al. [3] reported the TCC air voids characterization on the basis of volume, size distribution, shape and spacing, concluding that they had a strong influence on the strength and density.

In this paper, the internal air-void structure of GECC aerated by A and R (ground and included in the FCC milling treatment), after 7 days of curing in the wet chamber (wC) was compared. The following criteria to distinguish the range of pores were considered: micropores or pores less than or equal to $0.1 \mathrm{~mm}$ and macropores or pores greater than $0.1 \mathrm{~mm}$. The area analysed for each image was $16 \mathrm{~cm}^{2}$, and the number of different size pores was counted.

The GAwc7d sample (aerated with A) presented a predominance of 20-60 $\mu \mathrm{m}$ micropores located in the solid phases between the macropores with a homogeneous distribution and with no interconnection among them (Fig. 7.a). Regarding the macro scale, the predominant pore size is $0.3-2 \mathrm{~mm}$ with the presence of few macropores over $5 \mathrm{~mm}$ (Fig. 7.b). In general, this GECC presents an 
average of 677 pores in the $16 \mathrm{~cm}^{2}$ area, with an average diameter equal to $595 \mu \mathrm{m}$ and a predominant number of pores between 300-600 $\mu \mathrm{m}$ (Fig. 7.c).

Due to the fast reaction of commercial aluminium in the geopolymer matrix, there is a large amount of macropores and the surrounding solid material among them contained small non-interconnected micropores. This configuration may prove the low natural density obtained in GAwc7d mixtures as well as this low compressive strength.
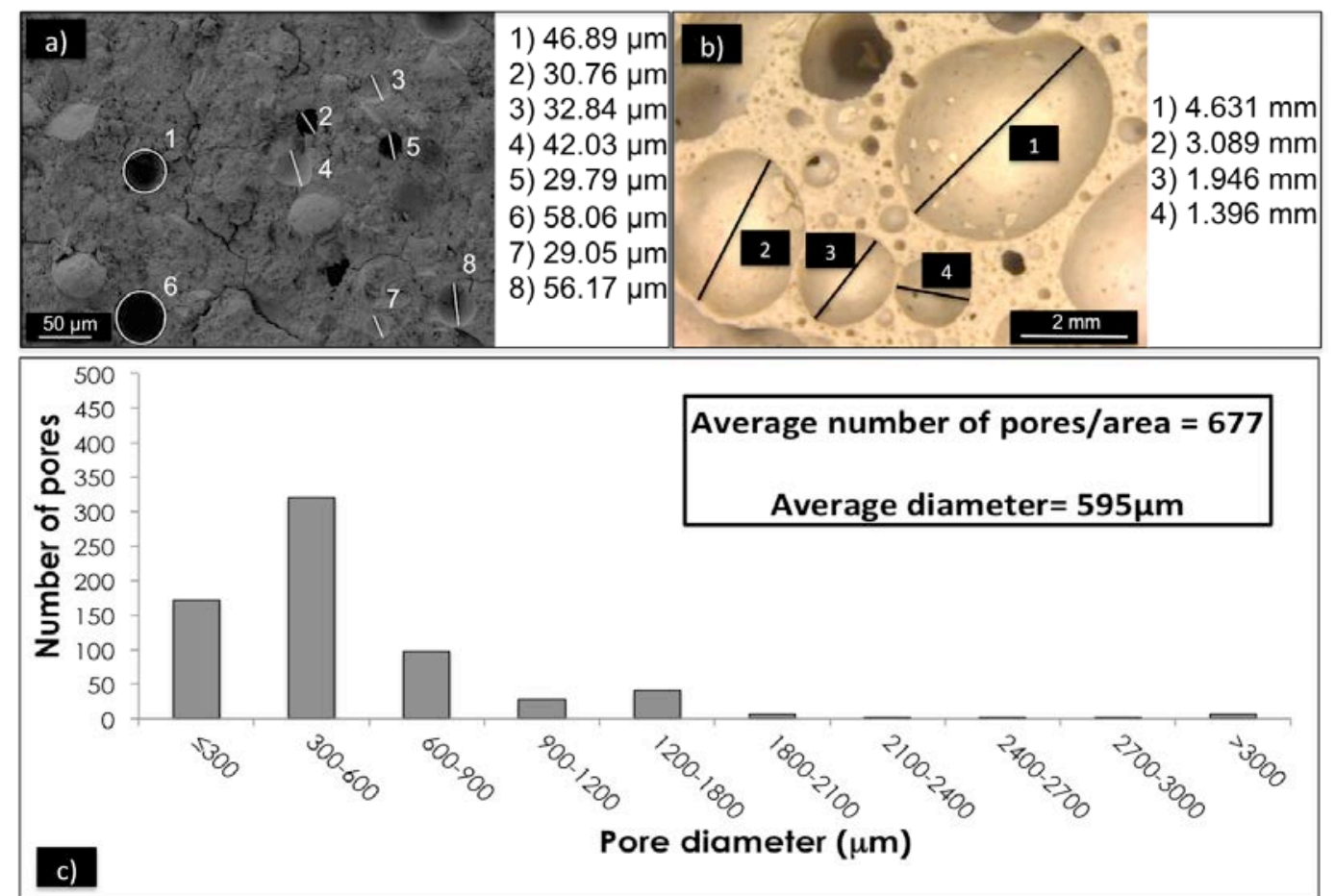

Fig. 7. Pore system characterization of GAwc7d: a) FESEM micropores sizing; b) OM macropores sizing; c) pore diameter distribution in $16 \mathrm{~cm}^{2}$ area.

The GRwc7d sample presents a predominance of 30-00 $\mu \mathrm{m}$ micropores that have irregular distribution and with some interconnection among them (Fig. 8.a). Regarding the macro scale, the predominant pore size is $1-5 \mathrm{~mm}$ with the presence of some $0.3-0.8 \mathrm{~mm}$ micropores inside the internal walls (Fig. 8.b). In general, this GECC presents an average of 455 pores in the $16 \mathrm{~cm}^{2}$ area, with an average diameter equal to $890 \mu \mathrm{m}$ and a predominant number of pores of $600-900 \mu \mathrm{m}$ (Fig. 8.c). These values observed in Fig. $8 \mathrm{c}$ are very different from those obtained in the GAwc7d sample.

This configuration reveals the lower aeration effectiveness in the matrix with the addition of $\mathrm{R}$ compared to the results obtained from the GAwc7d analysis. The interconnection between pores and their irregular shapes show that the big particles of $\mathrm{R}$ caused an aggressive and more localized reaction, and the entrapping of $\mathrm{H}_{2}$ released into the fresh matrix cannot be guaranteed.

Finally, with the use of $\mathrm{FCC}_{\mathrm{RM}}$ as the precursor, a similar pore structure to that obtained in the GA sample has been achieved. The GFCC $_{\text {RMWC }} 7 \mathrm{~d}$ sample presents a homogeneous micropore distribution with sizes of 20-100 $\mu \mathrm{m}$ (Fig. 9.a). Regarding the macro scale, the predominant pore sizes of 1-1.5 mm show some macropores interconnection (Fig. 9.b). This GECC presents an average number of 981 pores in 
the $16 \mathrm{~cm}^{2}$ area, with an average diameter equal to $373 \mu \mathrm{m}$ and a predominant number of pores smaller than $300 \mu \mathrm{m}$ (Figure 9.c).
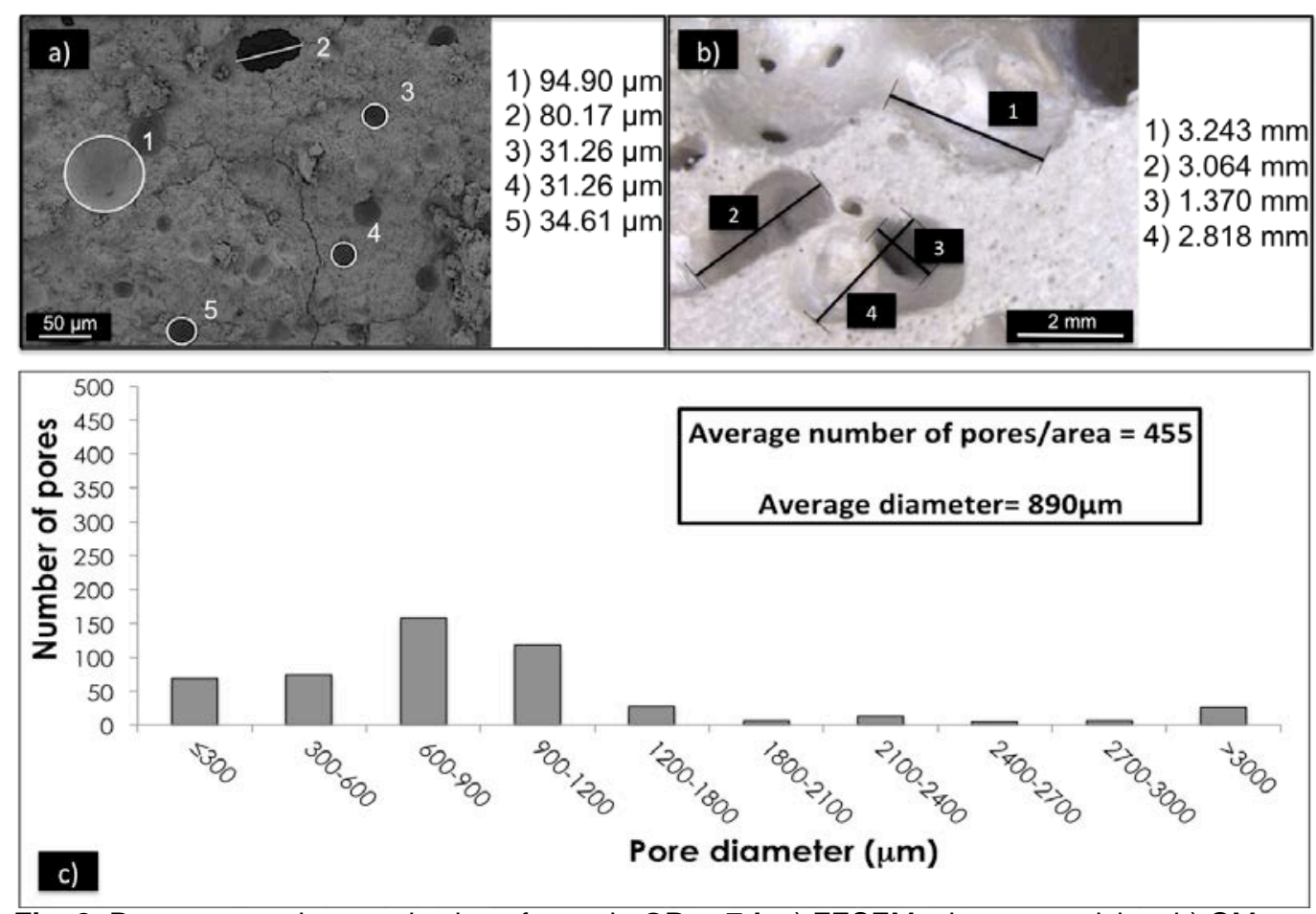

Fig. 8. Pore system characterization of sample GRwc7d: a) FESEM micropores sizing; b) OM macropores sizing; c) pore diameter distribution in $16 \mathrm{~cm}^{2}$ area.
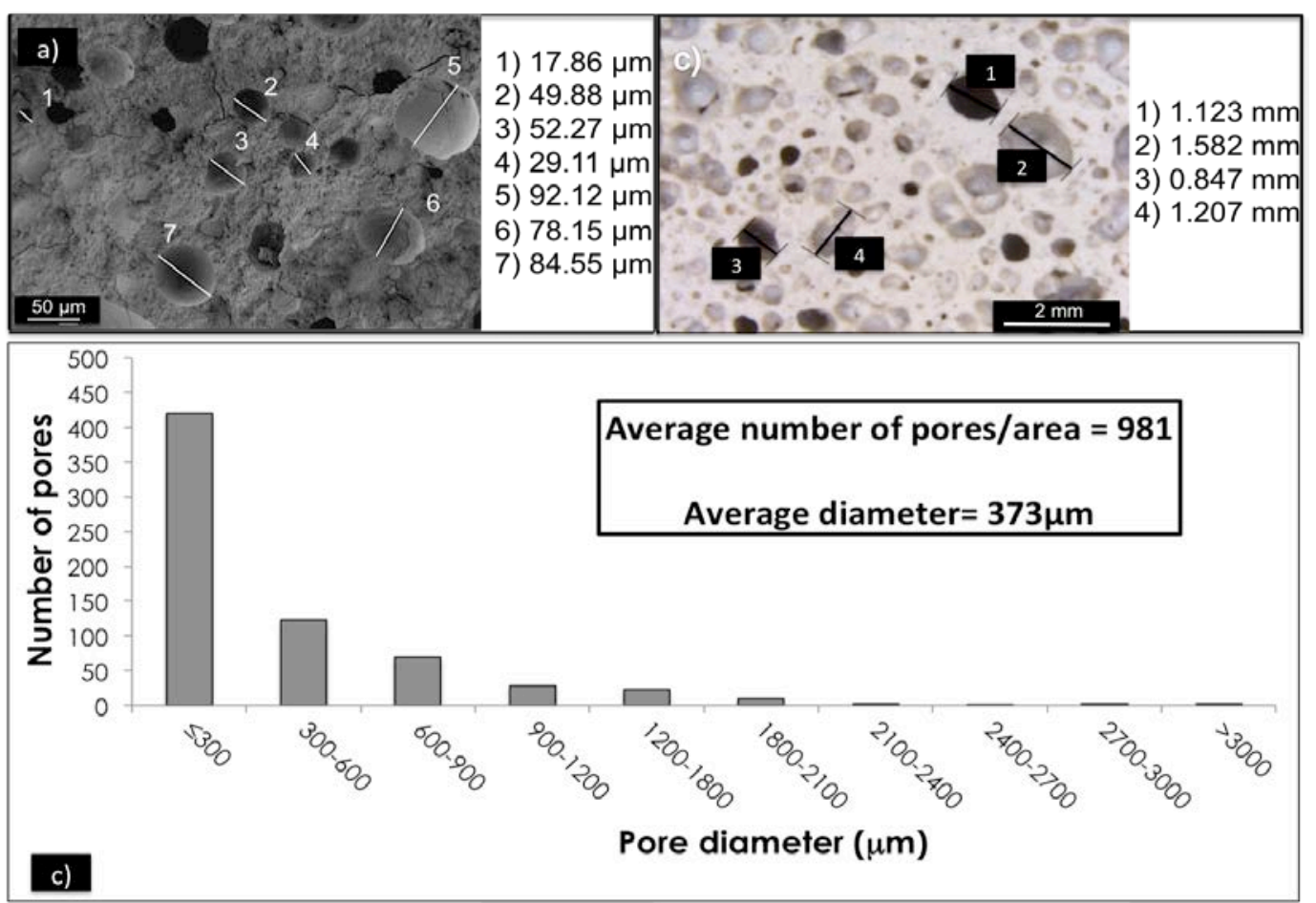

Fig. 9. Pore system characterization of sample GFCC $_{\text {RMWc7d: }}$ a) FESEM micropores pore sizing; $b$ ) OM macropores pore sizing; c) pore diameter distribution in $16 \mathrm{~cm}^{2}$ area 
In general, the inclusion of R in FCC milling achieved a better uniform size and distribution of pores in GECC, correlating highly with the density and strength values. The high number of micro and macropores is the cause of the low density of the material. However, given the existing interconnections among several of the macropores, its natural density was slightly greater than that obtained for the GAwc7d mixture. The predominance of micropores in the spaces between macropores leads to better mechanical properties.

\subsection{Hydric tests}

The thermal conductivity in cellular concrete is the consequence of its light weight due to the hydrogen bubbles trapped in the matrix paste. The bulk density is the main parameter that determines the amount of these pores in the final material [9].

On the other hand, regarding porosity, the proportion of closed porosity ( $\Phi C L)$ has a direct influence on the thermal insulation behaviour due to the hindrance of air circulation through the pores network. Contrarily, a higher proportion of open porosity (ФOP) can favour liquid or gas access into the matrix and its circulation. Finally, the total porosity (ФT) allows better acoustic insulation conditions.

The samples compared in this test were: TCC aerated by commercial aluminium powder and cured in the wet chamber for 7 days (TAwc7d) and GECC aerated by: commercial aluminium powder, recycled aluminium powder and recycled aluminium powder milled with FCC, cured in the wet chamber for 7 days (GAwc7d, GRwc7d and

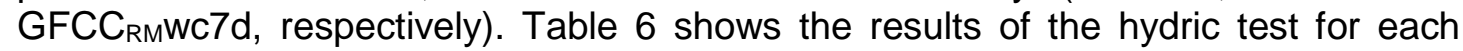
one.

Table 6 Results of hydric tests.

\begin{tabular}{|c|c|c|c|c|c|c|c|}
\hline \multirow{2}{*}{ Sample } & \multirow{2}{*}{$\begin{array}{l}\text { Bulk density } \\
\qquad\left(\mathrm{kg} / \mathrm{m}^{3}\right)\end{array}$} & \multicolumn{4}{|c|}{ Porosity (\%) } & \multirow{2}{*}{$\begin{array}{c}\text { Compactness } \\
(\%) \\
\text { C }\end{array}$} & \multirow{2}{*}{$\begin{array}{c}\text { Water } \\
\text { absorption } \\
(\%) \\
\mathrm{e}\end{array}$} \\
\hline & & ФТ & ФОР & $\Phi C L$ & $\frac{\Phi O P}{\Phi C L}$ & & \\
\hline TAwc7d & 710 & 65.62 & 47.20 & 18.42 & 2.56 & 34.38 & 67.32 \\
\hline GAwc7d & 680 & 74.68 & 51.55 & 23.13 & 2.22 & 25.33 & 47.10 \\
\hline GRwc7d & 790 & 59.67 & 52.22 & 7.46 & 7 & 40.33 & 41.05 \\
\hline GFCC $_{\text {RMWC7d }}$ & 630 & 69.14 & 46.03 & 23.11 & 1.15 & 30.85 & 59.30 \\
\hline
\end{tabular}

The greatest compactness values were for the lowest total porosity values, indicating the acoustic insulation properties of each GCC compared to TCC. As expected, due to the high purity of $A$ and the elevated alkaline medium, GAwc7d presents the highest total porosity and the lowest compactness.

Regarding open porosity and water absorption, the GRwc7d mixture had the greatest open porosity proportion, but its water absorption was the lowest. These results are in agreement with this pore system configuration regarding the interconnection and irregular macropores and, obviously with the lowest total porosity. In this context, for

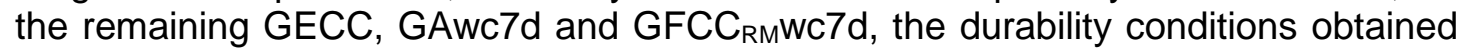

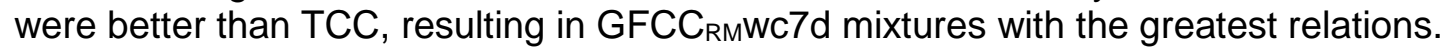
In general, lower values of bulk density correspond with a lower ratio between open and closed porosity. This ratio shows the amount of air entrapped due to the aeration reaction. Both GAwc7d and GFCC $C_{R M W C 7 d}$ were found to have a high closed porosity proportion and therefore had lower bulk densities values than that found for TAwc7d. This behaviour reveals the better thermal insulating properties of GECC with respect 
to TCC. Accordingly, it should be noted that the results of GFCC $_{\text {RMWC7d confirm the }}$ ecoefficiency advantages of this new environmentally friendly material.

\subsection{Thermal conductivity}

The thermal conductivity $(k)$ measurements for selected GECC systems are shown in Table 7. Four samples of each type were measured. As can be seen, the thermal conductivity of GRwc7d $(0.700 \mathrm{~W} / \mathrm{mK})$, for which aluminium foil is dry added to the precursor, was higher than that found for GECC aerated by commercial aluminium powder, GAwc7d $(0.622 \mathrm{~W} / \mathrm{mK})$, a behaviour attributed to the large difference in terms of natural density $\left(983 \mathrm{~kg} / \mathrm{m}^{3}\right.$ versus $\left.590 \mathrm{~kg} / \mathrm{m}^{3}\right)$. Interestingly, when aluminium foil is added into the FCC milling process (GFCC $\mathrm{RMWC}_{\mathrm{R}} \mathrm{d}$ ), the thermal conductivity results were the lowest (mean value $0.581 \mathrm{~W} / \mathrm{mK}$ ), although its natural density (690 $\mathrm{kg} / \mathrm{m}^{3}$ ) was slightly higher than that obtained for the GAwc7d system. Obviously, this behaviour may be related to the amount of pores, their size and their distribution (the finer the pores, the better the insulation) [2]. These results are in agreement with data collected from the hydric tests.

In general, the use of FCC as raw material and the introduction of recycled aluminium foil have been able to produce cellular concretes with great insulation properties. Notice that the co-milling process of FCC+R allows the insulation properties of the material to be improved when compared to the use of commercial aluminium powder. The $\mathrm{GFCC}_{\mathrm{RM}} 7 \mathrm{~d}$ mixtures resulted in the lowest thermal conductivities and consequently the greatest thermal insulation. This fact is directly related with energy saving terms.

Table 7 Individual and mean thermal conductivity values (k) for GECC samples.

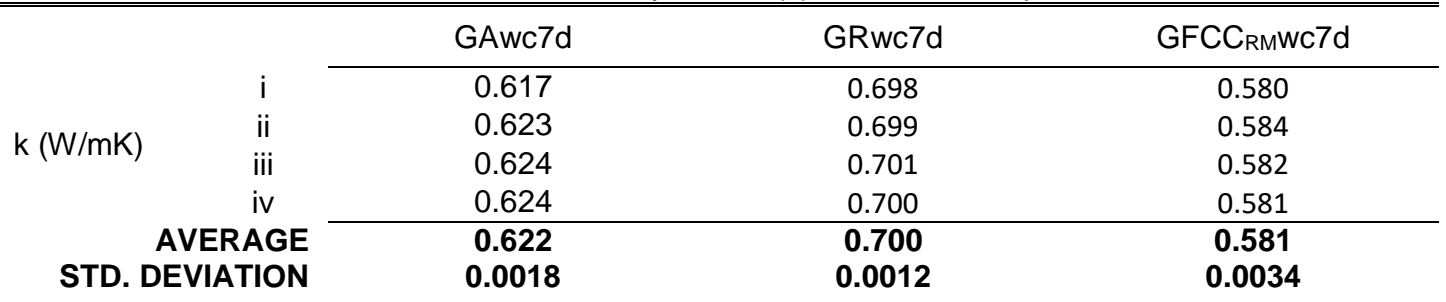

\section{Conclusions}

Cellular concrete based on alkali-activated FCC has been designed and tested, concluding that stable aerated concrete can be obtained in soft conditions: i) at $23^{\circ} \mathrm{C}$ with $100 \% \mathrm{RH}$ and ii) at $65^{\circ} \mathrm{C}$ in a thermal bath. In general, good performance of this new type of cellular concrete was observed. This waste becomes an interesting raw material for cellular concrete purposes, thus opening a new method of waste valorization.

Comparisons with OPC-based cellular concrete (traditional system, TA) showed that the reaction of commercial aluminium powder in the characteristic alkaline medium of alkali-activated mixtures (geopolymer system, GA) is faster and thus more effective. This behaviour is attributed to the fact that most of the hydrogen in the GA system was produced before setting due to the high temperatures of the geopolymerization reaction, and consequently more bubbles developed and were entrapped in the fresh material. To achieve a similar gas development in the traditional system, thermal treatment of the fresh mixture must be carried out. 
From the additional ecoefficiency and sustainability points of view, the replacement of commercial aluminium powder $A$, which needs high technological development in its production and has a high energy cost, by recycled aluminium foil $(R)$ was successfully carried out.

The main reactivity characteristic of $R$ is the generation of hydrogen when it is introduced into an alkaline medium. A very simple method to measure the potential hydrogen evolution based on the Bernard calcimeter technique has been described and applied to this aluminium foil waste. It was also compared with the reactivity of A. Similar reactivity of both aluminium types was found.

Appropriate physical and mechanical characteristics for these new geopolymer ecocellular concretes (GECC) containing FCC and R were obtained. The replacement of $0.2 \%$ of $A$ by the same amount of $R$ made it possible to produce cellular concrete with a natural density in the range of $500-1000 \mathrm{~kg} / \mathrm{m}^{3}$ and with compressive strength in the range of $2-4 \mathrm{MPa}$.

Specifically, the effectiveness of $\mathrm{R}$ was enhanced when this aluminium waste was co-milled with FCC: in these conditions, the particle size of the aluminium was significantly lower and the size and distribution of pores in the hardened cellular concrete were valuably improved. GECC prepared with co-milled FCC/R led to the production of the material with the best performance from the insulation point of view: an average pore diameter of $373 \mu \mathrm{m}$, a predominance of pores smaller than $300 \mu \mathrm{m}$, the lowest open/closed porosity ratio (1.15) and the lowest thermal conductivity $(0.581 \mathrm{~W} / \mathrm{mK})$.

In summary, an interesting way has been opened for reusing both FCC as precursor and aluminium foil waste as a foaming agent in the preparation of new geopolymer eco-cellular concretes (GECC).

\section{Acknowledgements}

This work was developed within the scope of the project Geocelplus (internal project, Universitat Politècnica de València). The authors give special grateful to Dra. Mrs. Josefa L. Roselló Caselles for kindly support and recycled aluminium foil supply. The authors also thank the Electron Microscopy Service of the Universitat Politècnica de València (Spain).

\section{References}

[1] A.S. Aguilar, J.P. Melo, F.H. Olivares, Microstructural analysis of aerated cement pastes with fly ash, metakaolin and sepiolite additions, Construction and Building Materials, 47 (2013) 282-292, http://dx.doi.org/10.1016/j.conbuildmat.2013.05.082.

[2] N. Narayanan, K. Ramamurthy, Structure and properties of aerated concrete: A review, Cement and Concrete Composites 22 (2000) 321-329, http://dx.doi.org/10.1016/S0958-9465(00)00016-0.

[3] K. Ramamurthy, E.K.K. Nambiar, G.I.S. Ranjani, A classification of studies on properties of foam concrete, Cement and Concrete Composites 2009; 31 (2009) 388396, http://dx.doi.org/10.1016/j.cemconcomp.2009.04.006. 
[4] M.R. Jones, A. McCarthy, Behavior and assessment of foamed concrete for construction applications. In: Dhir RK, Newlands MD, McCarthy A, editors. Use of foamed concrete for construction applications: Thomas Telford, 2005; 61-88, http://dx.doi.org/10.1680/uofcic.34068.0008.

[5] W. Wongkeo, P. Thongsanitgarn, K. Pimraska, A. Chaipanich, Compressive strength, flexural strength and thermal conductivity of autoclaved concrete block made using bottom ash as cement replacement materials, Materials and Design, 35 (2005) 434-439, http://dx.doi.org/10.1016/..matdes.2011.08.046.

[6] E. Namsone, G. Sahmenko, A. Korjakins, Durability Properties of High Performance Foamed Concrete, Procedia Engineering, 172 (2017) 760 -767, https://doi.org/10.1016/j.proeng.2017.02.120.

[7] P.J. Tikalsky, J. Pospisil, W. MacDonald, A method for assessment of the freezethaw resistance of performed foam cellular concrete, Cement and Concrete Research 34, 4 (2004) 889-93, http://dx.doi.org/10.1016/j.cemconres.2003.11.005.

[8] L. Tanaçan, H.Y. Ersoy, Ü. Arpacioglu, Effect of high temperature and cooling conditions on aerated concrete properties, Construction and Building Materials, 23 (2009) 1240-1248, http://dx.doi.org/10.1016/j.conbuildmat.2008.08.007

[9] J.P. Melo. Desarrollo y caracterización de un material celular de alta porosidad con base cementicia activada mediante agentes inorgánicos. Tesis doctoral, Universidad Politécnica de Madrid (in Spanish). 2013. http://oa.upm.es/22562/ (accessed 24.03.17)

[10] B. Dolton, C. Hannah, Cellular concrete: engineering and technological advancement for construction in cold climates. In: Proc. Annual General Conference of the Canadian Society for Civil Engineering, Calgary Alberta, Canada 2006; 1-11. http://www.clcir.com/index.php/download/cold (accessed 24.03.17)

[11] F. Zulkarnain, M. Ramli, Durability of performance of foamed concrete mix design with silica fume for housing development, Journal of Materials Science and Engineering 5 (2011) 518-527.

[12] A.J. Hamad, Materials, production, properties and application of aerated lightweight concrete: Review, International Journal of Materials Science and Engineering, 2 (2014) 152-157, http://dx.doi.org/10.12720/ijmse.2.2.152-157.

[13] K.H. Mo, U.J. Alengaram, M.Z. Jumaat, S.P. Yap, S.C. Lee, Green concrete partially comprised of farming waste residues: a review, Journal of Cleaner Production 117 (2016) 122-138, http://dx.doi.org/10.1016/j.jclepro.2016.01.022.

[14] F. Puertas, M. Torres-Carrasco, Use of glass waste as an activator in the preparation of alkali-activated slag. Mechanical strength and paste characterisation, Cement and Concrete Research, 57 (2014) 95-104. http://dx.doi.org/10.1016/i.cemconres.2013.12.005.

[15] J.G. Sanjayan, A. Nazari, L. Chen, G.H. Nguyen, Physical and mechanical properties of lightweight aerated geopolymer, Construction and Building Materials 79 (2015) 236-244, http://dx.doi.org/10.1016/j.conbuildmat.2015.01.043.

[16] C. Bai, G. Franchin, H. Elsayed, A. Conte, P. Colombo, High strength metakaolin-based geopolymer foams with variable macroporous structure, Journal of 
the European Ceramic Society 36 (2016) 4243-4249, http://dx.doi.org/10.1016/j.jeurceramsoc.2016.06.045.

[17] Z. Zhang, J.L. Provis, A. Reid, H. Wang, Geopolymer foam concrete: an emerging material for sustainable construction, Construction and Building Materials, 56 (2014) 113-127, http://dx.doi.org/10.1016/j.conbuildmat.2014.01.081.

[18] P. Hlavácek, V. Smilauer, F. Skvára, L. Kopecký, R. Sulc, Inorganic foams made from alkali-activated fly ash: Mechanical, chemical and physical properties, Journal of the European Ceramic Society 35 (2015) 703-709, http://dx.doi.org/10.1016/j.jeurceramsoc.2014.08.024.

[19] R.A. Aguilar, O.B. Díaz, J.I.E García, Lightweight concretes of activated metacaolin-fly ash binders with blast furnace slag aggregates, Construction and Building Materials 24 (2009) 1166-1175, http://dx.doi.org/10.1016/j.conbuildmat.2009.12.024.

[20] P. Keawpapasson, C. Tippayasam, S. Ruangjan, P. Thavorniti, T. Panyathanmaporn, A. Fontaine, C. Leonelli, D. Chaysuwan, Metakaolin-Based Porous Geopolymer with Aluminum Powder, Key Engineering Materials 608 (2014) 132-138, http://dx.doi.org/10.4028/www.scientific.net/KEM.608.132.

[21] H. Esmaily, H. Nuranian, Non-autoclaved high strength cellular concrete from alkali activated slag, Construction and Building Materials 26 (2012) 200-206, http://dx.doi.org/10.1016/j.conbuildmat.2011.06.010.

[22] J. Payá, J. Monzó, M.V. Borrachero, Fluid catalytic cracking catalyst residue (FC3R). An excellent mineral by-product for improving early strength development of cement mixtures, Cement and Concrete Research 29 (1999) 1773-1779, http://dx.doi.org/10.1016/S0008-8846(99)00164-7.

[23] J. Payá, M.V Borrachero, J. Monzó, L. Soriano, Studies on the behavior of different spent fluidized-bed catalytic cracking catalysts on Portland cement, Building Materials, 296 (2009) 37-52, http://dx.doi.org/10.3989/mc.2009.48108.

[24] J. Payá, J. Monzó, M.V. Borrachero, S. Velázquez, M. Bonilla, Determination of the pozzolanic activity of fluid catalytic cracking residue. Thermogravimetric analysis studies on FC3R-lime pastes, Cement and Concrete Research 33 (2003) 1085-1091, http://dx.doi.org/10.1016/S0008-8846(03)00014-0.

[25] M.M. Tashima, J.L. Akasaki, V.N. Castaldelli, L. Soriano, J. Monzó, J. Payá, M.V. Borrachero, New geopolymeric binder based on fluid catalytic cracking catalyst residue (FCC), Materials Letters 80 (2012) 50-52, http://dx.doi.org/10.1016/j.matlet.2012.04.051.

[26] The Economic Impact of Aluminum. In: The Aluminum Association. http://www.aluminum.org/aluminum-advantage/economic-impact-aluminum (accessed 24.03.17).

[27] S.H. Hong, D.W. Lee, B.K. Kim, Manufacturing of aluminum flake powder from foil scrap by dry ball milling process, Journal of Materials Processing Technology, 100 (2000) 105-109, http://dx.doi.org/10.1016/S0924-0136(99)00469-0. 
[28] E.G Araújo, J.A.S Tenório, Cellular concrete with addition of aluminum recycled foil powders, Materials and Science Forum, 498-499 (2005) 198-204, http://dx.doi.org/10.4028 / www.scientific.net / MSF.498-499.198.

[29] E. Holt and P. Raivio, Use of gasification residues in aerated autoclaved concrete, Cement and Concrete Research, 35 (2005) 796-802, http://dx.doi.org/10.1016/j.cemconres.2004.05.005.

[30] Y. Song, B. Li, E.H. Yang, Y. Liu and T. Ding, Feasibility study on utilization of municipal solid waste incineration bottom ash as aerating agent for the production of autoclaved aerated concrete, Cement and Concrete Composites, 56 (2015) 51-58, http://dx.doi.org/10.1016/j.cemconcomp.2014.11.006.

[31] ISO 10693:1995: Soil quality - Determination of carbonate content - Volumetric method. International Organization for Standardization. 